\title{
Coping WiTh CHILE'S EXTERNAL VULNERABILITY: A Financial Problem
}

\author{
Ricardo J. Caballero \\ Massachusetts Institute of Technology \\ and National Bureau of Economic Research
}

With traditional domestic imbalances long under control, the Chilean business cycle is driven by external shocks. Chile's external vulnerability is primarily a financial problem. A decline in the Chilean terms of trade, for example, is associated with a decline in real gross domestic product (GDP) that is many times larger than one would predict in the presence of perfect financial markets. The financial nature of this excess sensitivity has two central dimensions: a sharp contraction in Chile's access to international financial markets when it needs it the most and an inefficient reallocation of this scarce access across borrowers during external crises. I argue that Chile's aggregate volatility can be reduced significantly by fostering the private sector's development of financial instruments that are contingent on the main external shocks faced by Chile. As a first step, the Central Bank or international financial institutions could issue a benchmark instrument contingent on these shocks. I also advocate a countercyclical monetary policy (also contingent on these shocks), but mainly as an incentive - that is, as a substitute for taxes on capital inflows and equivalent-rather than for ex post liquidity purposes.

The essence of the mechanism through which external shocks affect the Chilean economy can be characterized as follows. First, a deterioration of the terms of trade raises the need for external re-

I am very grateful to Vittorio Corbo, Esteban Jadresic, and Norman Loayza for their comments; to Adam Ashcraft, Marco Morales, and especially Claudio Raddatz for excellent research assistance; and to Herman Bennett for his effort collecting much of the required data.

Economic Growth: Sources, Trends, and Cycles, edited by Norman Loayza and Raimundo Soto, Santiago, Chile. (c) 2002 Central Bank of Chile. 
sources if the real economy is to continue unaffected, but this triggers exactly the opposite reaction from international financiers, who pull back capital inflows. The latter occasionally occurs directly as a contagion effect. Second, once external financial markets fail to accommodate the needs of domestic firms and households, these agents turn to domestic financial markets, in particular to commercial banks. Again, this increase in demand is not matched by an increase in supply since banks-particularly resident foreign institutions-tighten domestic credit, opting instead to increase their net foreign asset positions. Third, the domestic financial system experiences a significant "flight to quality," which reinforces the above effects as large firms find it more attractive to seek financing in domestic markets, while the displaced small and medium-sized firms cannot access international financial markets at any price.

The costs of this mechanism are high. Widespread financial constraints are binding during the crisis, when major forced adjustments are needed. The sharp decline in domestic asset prices, and the corresponding rise in expected returns, is driven by the extreme scarcity in financial resources and their high opportunity cost. Even the praised rise in foreign direct investment (FDI) that occurred during the most recent crisis is a symptom of these fire sales. The fact that this investment takes the form of control purchases rather than portfolio or credit flows simply reflects some of the underlying problems that limit Chile's integration to international financial markets: weak corporate governance and other "transparency" standards. Finally, the costs do not end with the crisis, since financially distressed firms are ill equipped to mount a speedy recovery. The latter often comes not only with the costs of a slow recovery in employment and activity, but also with a slowdown in the process of creative destruction and productivity growth. In the United States, the latter may account for about 30 percent of the costs of an average recession (see Caballero and Hammour, 1998), which is probably a very optimistic lower bound for the Chilean economy. Moreover, the presence of a severely large number of financially distressed small firms reduces rather than enhances the effectiveness of monetary policy in facilitating the recovery.

The distributional impact of this type of crisis is significant, as well. On one end, large firms are directly affected by external shocks, but they can substitute most of their financial needs domestically. They are affected primarily by demand factors. On the other, small and medium-sized enterprises (henceforth, SMEs) are crowded out and are se- 
verely constrained on the financial side. They are the residual claimants of the financial crunch.

This diagnosis points in the direction of a structural solution based on two building blocks. The first deals with the institutions required to foster Chile's integration to international financial markets and the development of domestic financial markets. Chile is making significant progress along this margin through its capital markets reform program. The second building block, which is necessary because of the unavoidably slow nature of the above process, is to design an appropriate international liquidity management strategy. This strategy must be understood in broader terms than the Central Bank's management of international reserves, and it must include the development of financial instruments that facilitate the delegation of this task to the private sector.

I focus on the latter type of solution in this paper. ${ }^{1}$ I view the policy problem as one of remedying a chronic private sector underinsurance with respect to external crises. ${ }^{2}$ After outlining the main sources of this problem and the corresponding solutions, I focus on two. First, to develop a key missing market, I propose the creation of a benchmark bond that is contingent on the main external shocks faced by Chile. This instrument should facilitate the private sector's pricing and creation of similar and derivative contingent financial instruments. Second, I discuss optimal monetary policy and international reserve management from an insurance perspective. Provided that the Central Bank of Chile has achieved a high degree of inflation-target credibility, the optimal response to an external shock is a moderate injection of reserves and an expansionary monetary policy. The latter, however, is unlikely to have a large real impact and indeed will imply a sharp, short-lived exchange rate depreciation. The main benefit of such a policy is in the incentives it provides. The main problem is that it is time inconsistent.

The following section describes the essence of the external shocks and the financial mechanism at work. Section 2 follows with a discussion of the impact of this mechanism on the real side of the economy and the different economic agents. Section 3 discusses policy options, and section 4 concludes.

1. See Caballero $(1999,2001)$ for a discussion of the structural reforms aimed at improving integration and the development of financial markets. More important, Chile is in the process of enacting a major capital markets reform.

2. See Caballero and Krishnamurthy (2001c) for a formal discussion of this perspective. 
Table 1. The Relative Importance of Bank Loans ${ }^{\text {a }}$

Percent

\begin{tabular}{lcc}
\hline Source of financing & Stock & Flows \\
\hline Loans & 43 & 51 \\
Equity & 54 & 33 \\
Bonds & 3 & 16 \\
\hline
\end{tabular}

a. Participation levels were built using the stocks from December 2000. Flows were computed as the difference in stocks between December 1999 and December 2000, except for the flow of new equity, which was built using information on equity placement during the period.

\section{The Shock And the Financial System}

This section illustrates the mechanism through which external shocks affect the Chilean economy. I start off with a brief description of the Chilean financial sector. I then organize the discussion of the role played by the shocks and their amplification mechanisms around demand and supply factors affecting the domestic banking system - the backbone of the Chilean financial system. Finally, I focus on the most recent cyclical episode, because the changing nature of the Chilean financial system makes older data less relevant.

\subsection{The Chilean Banking Sector}

Banks are an important source of financing for Chilean firms. The composition of financing is similar to that of advanced European economies (see table 1). The maturity structure of Chilean bank loans, however, is more concentrated on the short end: 57 percent of total loans and 60 percent of commercial loans have a maturity of less than one year. ${ }^{3}$ Chilean banks thus look like European banks in terms of their relative importance, but they are more similar to U.S. banks in their focus on short maturities. ${ }^{4}$

Chilean banks concentrate most of their activity on firms. Commercial loans represent around 60 percent of total bank loans. If trade loans are also taken into account, about 70 percent of total bank credit

3. Computed using the stock of loans in December 1999, as reported by the Superintendencia de Bancos e Instituciones Financieras.

4. In Germany, for example, more that 70 percent of the commercial loans are long term. In contrast, in the United States short-term loans account for about 60 percent of nonresidential loans. 
supply is directed to firms. The remainder is allocated to mortgages (15 percent), consumption loans (10 percent), and other types of loans (5 percent). ${ }^{5}$

Chilean banks concentrate their lending activity on large firms, at least when firm size is approximated by loan size. Large loans of over US\$1.4 million (in end-1999 dollars) capture 64 percent of the volume of commercial loans. In contrast, only 14 percent is allocated to medium-sized loans (between US $\$ 280,000$ and US $\$ 1.4$ million), while small loans (below US $\$ 280,000$ ) account for the remaining 22 percent. $^{6}$

Banks in Chile are important when compared with other financial institutions, as well. Banks' assets represent 60 percent of total assets, whereas pension funds control 30 percent and insurance companies 10 percent. $^{7}$

Within the banking sector, foreign banks maintain a very significant presence. Loans by foreign banks represented 42 percent of total loans in 1999, versus 58 percent for domestic banks. Portfolio composition is roughly similar among the two types of banks, with loans accounting for the largest share of assets (67 percent for foreign banks and 80 percent for domestic). Considerable differences are seen, however, in the relative importance of foreign assets ( 15 percent for foreign banks versus just 6 percent for domestic), securities (14 percent versus 11 percent), and reserves (4 percent versus 3 percent). ${ }^{8}$ Finally, note that Chilean Banking Law does not recognize subsidiaries of foreign banks as part of their main headquarters.

\subsection{The External Shock and Its Impact on Domestic Financial Needs}

The trigger of the mechanism is illustrated in figure 1. Panel A shows the path of Chile's terms of trade and the spread paid by prime Chilean instruments over the equivalent U.S. Treasury instrument. Chile was severely affected by both at the end of the 1990s. Panel B offers a better metric to gauge the magnitude of these shocks. Taking the quan-

5. Superintendencia de Bancos e Instituciones Financieras.

6. Superintendencia de Bancos e Instituciones Financieras.

7. Total assets are calculated as the sum of financial and fixed assets. Fixed assets are not included for insurance companies, but they represent a very small fraction of financial institutions' assets. Ratios are based on the stock of assets in December 2000, as reported by the Superintendencia de Bancos e Instituciones Financieras and the Superintendencia de Valores y Seguros.

8. Superintendencia de Bancos e Instituciones Financieras. 


\section{Figure 1. External Shocks ${ }^{a}$}

A. Terms of trade and sovereing spread

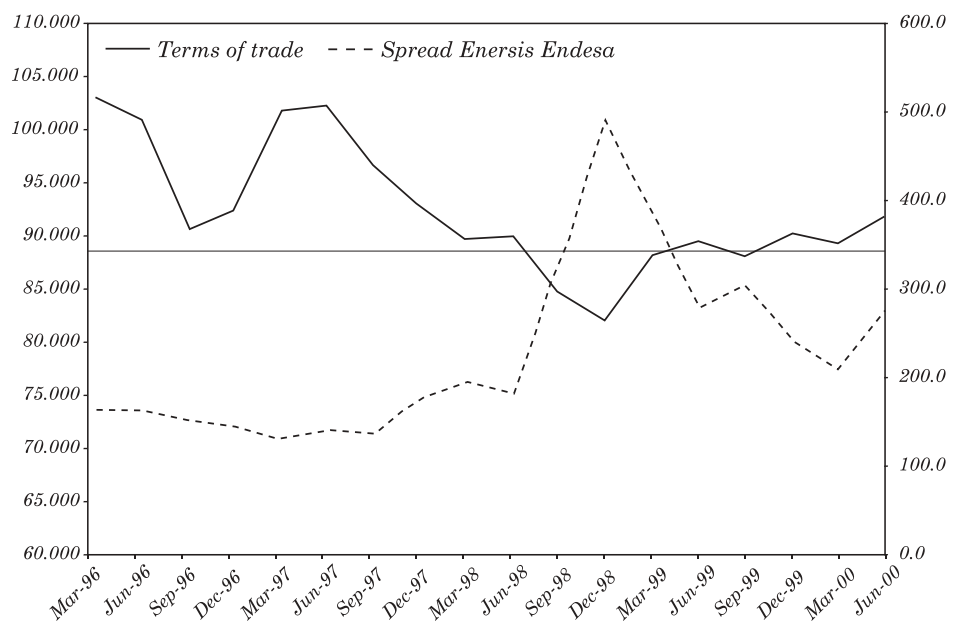

B. Terms of trade and interest rate effect ( fixed quantities)

Bn. US\$

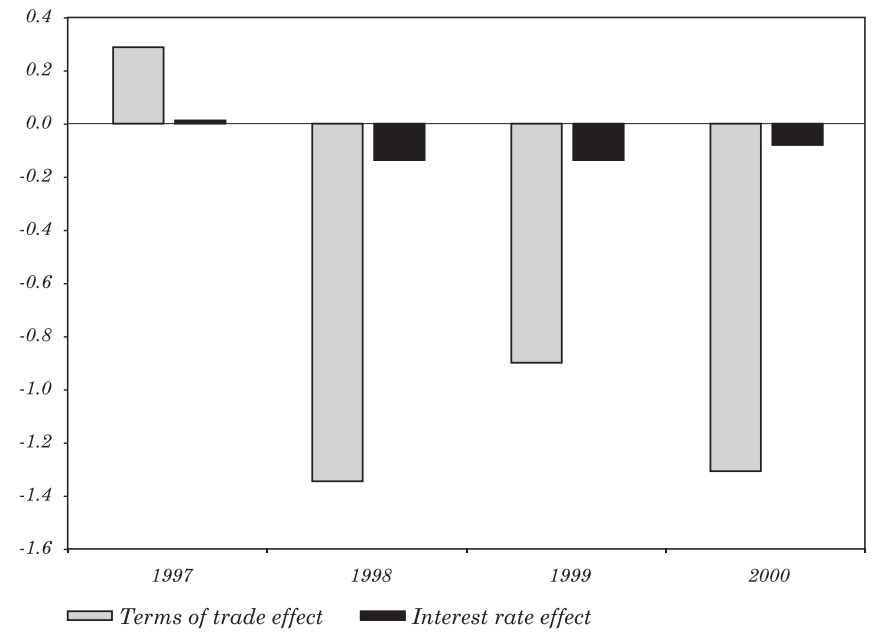

Source: Central Bank of Chile.

a. Preliminary data used for 1999 and 2000 . The yearly figure for 2000 was computed by multiplying the threequarter cummulative value by $4 / 3$. In panel A, terms of trade is the ratio of export price index and import price index computed by the Central Bank of Chile. The sovereign spread was estimated as the spread of ENERSISENDESA corporate bonds. The spread data for 1996 was estimated by the author using information from the Central Bank. In panel B, the terms-of-trade effect was computed as the difference between the actual terms of trade and the terms of trade at 1996 quantities. The interest rate effect was computed in similar fashion. 
Figure 2. Excess Sensitivity of Real Consumption Growth to Terms of Trade Shocks ${ }^{\text {a }}$

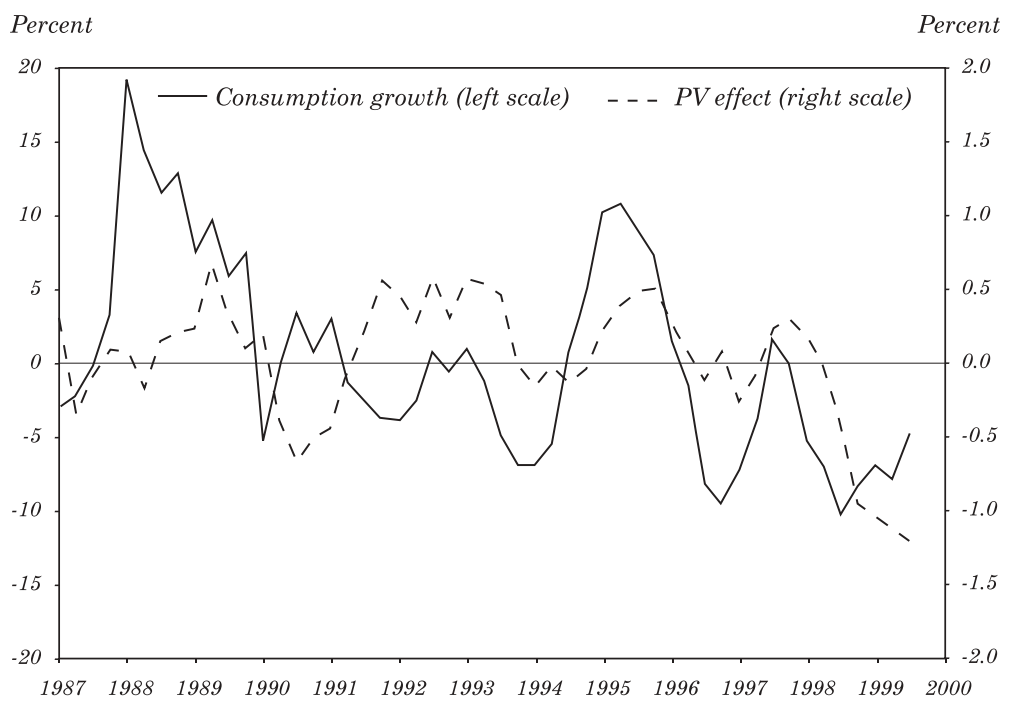

Source: Consumption growth: International Financial Statistics (IFS); copper prices (London Metal Exchange): Datastream; copper exports: Chile's Ministry of Finance.

tities from the 1996 current account as representative of those that would have occurred in the economy absent any real adjustment, it translates them into the dollar losses associated with the deterioration in the terms of trade and interest rates. These losses amounted to about two percent of GDP in 1998, with similar magnitudes for 1999 and 2000.

How should Chile have reacted to this sharp decline in national income, in the absence of any significant financial friction (aside from the temporary increase in the spread)? Figure 2 hints at the answer. The thick line depicts the path of Chile's actual consumption growth, while the broken line illustrates the hypothetical path of consumption growth if it were perfectly integrated with international financial markets and if the terms of trade were the only source of shocks. ${ }^{9}$ The figure has two interesting features. First, there is a

9. Consumption growth is very similar to GDP growth for this comparison. Adding the income effect of interest rate shocks would not change things too much, as these were very short lived. I neglect the presence of substitution effects because there is no evidence of a consumption overshooting once international spreads come down. 
very high correlation between Chile's business cycle and shocks to its terms of trade. This correlation is not observed in other commodity-dependent economies with more developed financial markets, such as Australia or Norway (see Caballero 1999, 2001). Second, and more important for the argument in this paper, the figure demonstrates that the economy overreacts to these shocks by a significant margin. In the figure, the actual response of the economy is measured on the left axis, while the hypothetical response is measured on the right axis; the scale of the former is fully ten times larger than that of the latter. In practice, terms-of-trade shocks are simply too transitory-especially when they are driven by demand, as in the recent crisis - to justify a large response from the real side of the economy. ${ }^{10}$ The income effect that is measured in panel B of Figure 1 should, in principle, translate almost entirely into increased borrowing from abroad, but it does not do so in practice.

Returning to the crisis of the late 1990s, panel A of figure 3 illustrates that international financial markets not only did not accommodate the (potential) increase in demand for foreign resources, but capital inflows actually declined rapidly over the period. While the Central Bank offset part of this decline by injecting back some of its international reserves, it clearly was not enough to offset both the decline in capital inflows and the rise in external needs (see panel B). For example, the figure shows that in 1998 , the injection of reserves amounted to approximately US $\$ 2$ billion. This is comparable to the direct income effect of the decline in the terms of trades and the rise in interest rates, but it does not compensate for the decline in capital inflows that came with these shocks.

How severe was the mismatch between the increase in needs and the availability of external financial resources? Panel A of figure 4 has a back-of-the-envelope answer. It graphs the actual current account (light bars) and the current account with quantities fixed at 1996 levels (dark bars). At the trough, in 1999, the actual current

10. The price of copper has trends and cycles at different frequencies, some of which are persistent (see Marshall and Silva, 1998). The sharp decline in the price of copper in the late $1990 \mathrm{~s}$, however, undoubtedly resulted primarily from a transitory demand shock brought about by the Asian and Russian crises. I would argue that conditional on the information that the current shock was a transitory demand shock, the univariate process used to estimate the present value impact of the decline in the price of copper in figure 2 overestimates the extent of this decline. The lower decline in futures prices is consistent with this view. The variance of the spot price is six times the variance of fifteen-month-ahead futures prices. Moreover, the expectations computed from the autoregression process track reasonably well with the expectations implicit in futures markets, except for the very end of the sample when liquidity premium considerations may have come into play. 
Figure 3. Capital Flows and Reserves

A. Capital account except reserves
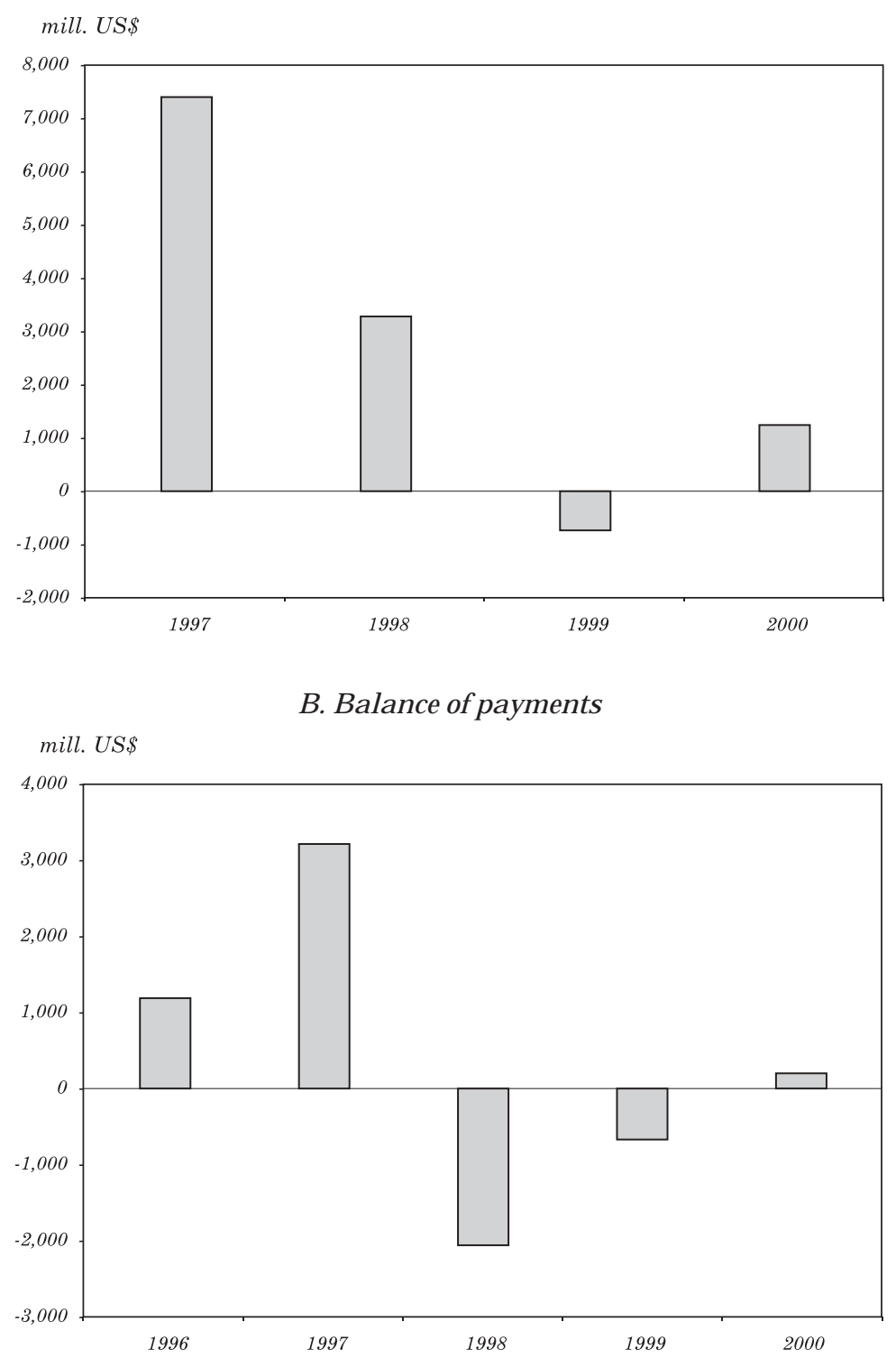

Source: Central Bank of Chile. 


\section{Figure 4. The Current Account ${ }^{\mathrm{a}}$}

A. Current account and current account at 1996 quantities mill US\$

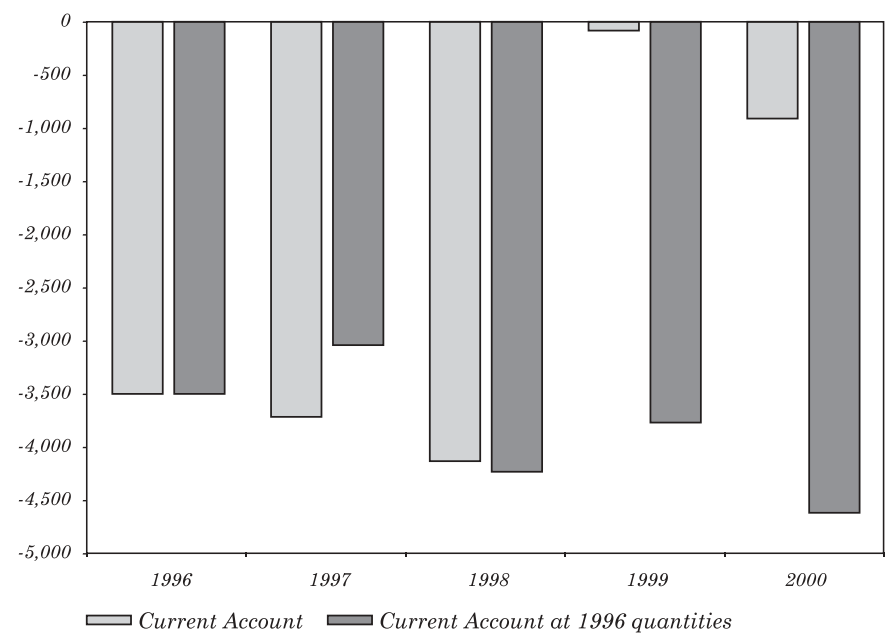

B. Current account (current and in 1996 prices)

mill. US\$

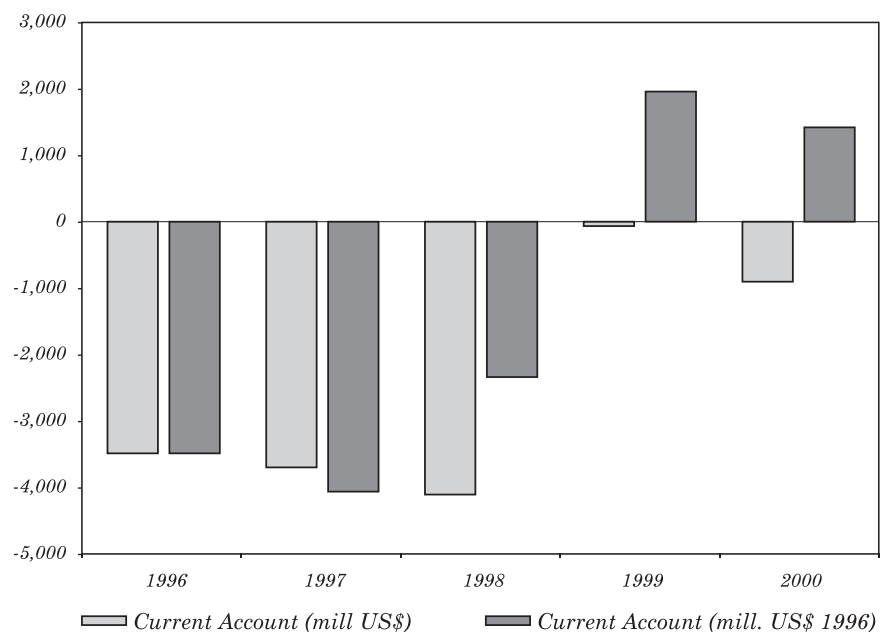

Source: Central Bank of Chile.

a. In panel A, the current account at 1996 quantities was computed by multiplying the 1996 quantities by each year's price indices for exports, imports, and interest payments. The other components of the current account were kept at current values. In panel B, the current account in 1996 prices was computed by multiplying the 1996 prices by each year's quantities. 


\section{Figure 5. The Increase in Potential Financial Needs ${ }^{a}$}

A. Comprehensive (mill. US\$)

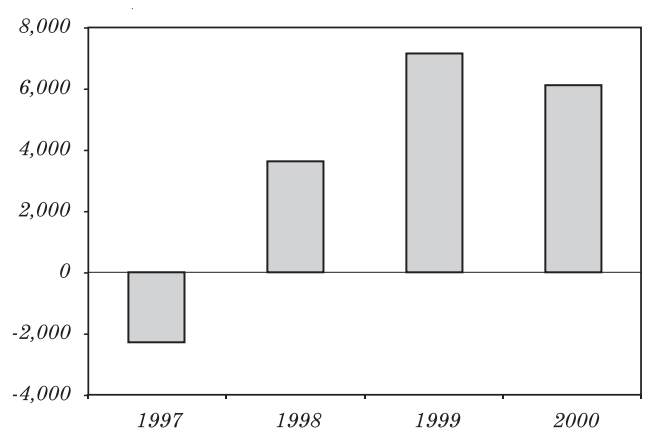

B. (A) minus reserves accummulation (mill. US\$)

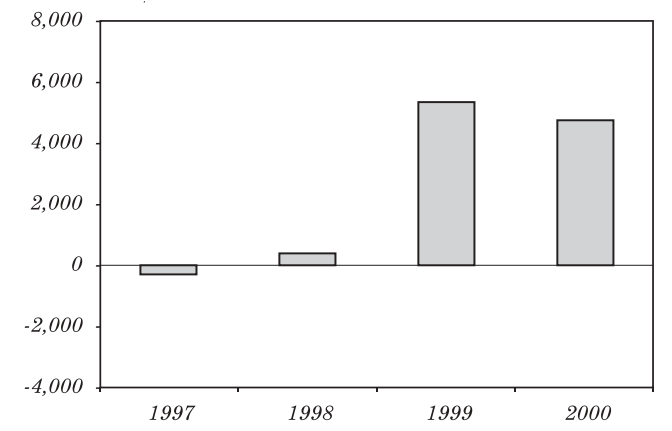

C. (B) minus flows to banking sector (mill. US\$)

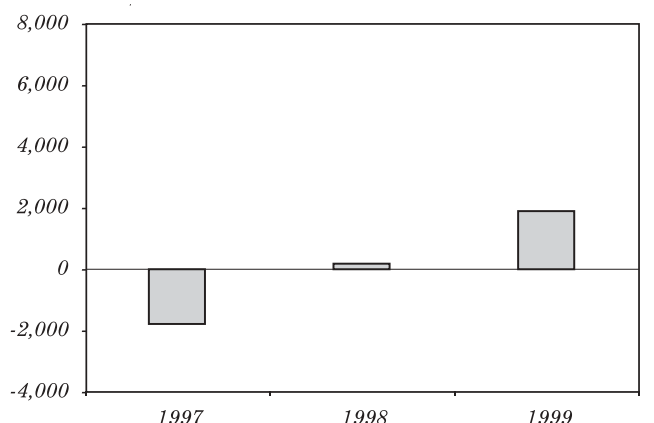

Source: Central Bank of Chile.

a. Panel A corresponds to the sum of the terms of trade effect, the interest rate effect, and the decline in capital inflows. Both the terms-of-trade and the interest rate effects are measured at 1996 quantities. The decline in capital flows corresponds to the difference of the capital account except reserves with respect to its 1996 value. Panel B subtracts from panel A the net change in Central Bank reserves. Panel C subtracts from panel B the net increase in flows to the banking sector. 
account deficit was around US\$4 billion less than what one would have predicted using only the actual change in terms of trade. Moreover, this dollar adjustment underestimates the quantity adjustment behind it, as the deterioration of the terms of trade typically worsens the current account deficit for any path of quantities. The importance of this price correction can be seen in panel B, which graphs the actual current account (light bars), and the current account at 1996 prices (dark bars). The latter clearly shows a significantly larger adjustment than the former.

Figure 5 reinforces the mismatch conclusion by reporting increasingly conservative estimates of the shortage of external financial resources by the nonbanking sector. Panel A describes the path of the change in potential financial needs stemming from the decline in the terms of trade and capital inflows, and the increase in spreads. Panel B subtracts from panel A the injection of reserves by the Central Bank, while panel C subtracts from panel B the decline in capital inflows to the banking sector. The increase in financial needs for 1999 ranges from about US $\$ 2$ billion to just above US $\$ 7$ billion. Regardless of the method used, the mismatch is large, which creates a potentially large surge in the demand for resources from the domestic financial system. The difference between panels $\mathrm{b}$ and $\mathrm{c}$ shows that the domestic financial sector not only did not accommodate this increase in demand, but also exacerbated the financial crunch.

Figure 6 illustrates additional dimensions that could have smoothed the demand for resources from resident banks, although they did not do so. Panels a and b carry the relatively good news. The former shows that issues of new equity and corporate bonds did not decline very sharply, although they hide the fact that the required return on these instruments rose significantly. The latter panel illustrates that while the pension funds increased their allocation of funds to foreign assets during the period, this portfolio shift occurred mostly against public instruments. However, this decline probably translated into a large placement of public bonds on some other market or institution that competes with the private sector, like banks (see the discussion below). Panel C, on the other hand, indicates that retained earnings, which are a significant source of investment financing to Chilean firms, declined significantly over the period. ${ }^{11}$ Finally, panel D illustrates that

11. Before the crises, in 1996, the stock of retained earnings represented 20 percent of total assets for the median firm. The difference between profits and dividend payments (a measure of the flow of retained earnings) represented around 50 percent of total capital expenditures for the median firm in 1996. 
workers did not help accommodate the financial bottleneck either, as the labor share rose steadily throughout the period.

The bottom line of this section is clear: during external crunches, firms need substantial additional financial resources from resident banks.

\subsection{The (Supply) Response by Resident Banks}

How did resident banks respond to increased demand? The short answer is that they exacerbated rather than smooth the external shock. Panel A in figure 7 shows that domestic loan growth actually slowed sharply in the late 1990s, even as deposits kept growing. This tightening can also be seen in prices, through the sharp rise in the loan-deposit spread during the early phase of the recent crisis (see panel B). While spreads started to fall by 1999 , the strong substitution toward prime firms makes it difficult to interpret this decline as a loosening in credit standards.

The main substitutes for loans in banks' portfolios are public debt and external assets (see figure 8, panel A). Banks clearly moved their assets toward external assets. Interestingly, the Central Bank policy of fighting capital outflows with high domestic interest rates was only temporarily successful, as evidenced by the reversal in the last quarter of 1998. The rise in interest rates during the Russian phase of the crisis seems to have succeeded mostly in slowing down the decline in banks' investment in public instruments, and it encouraged substitution away from loans. Banks exacerbated-rather than smoothed-the loss of external funding by becoming part of the capital outflows. In fact, while the banking sector also experienced a large capital outflow during this episode (see panel B), much of the net outflow was not due to a decline in their international credit lines or inflows, but rather to an outflow toward foreign deposits and securities (panel C).

Most resident banks exhibited this pattern to some degree, but resident foreign banks had the most pronounced portfolio shift toward foreign assets. This is apparent in panels a and b of figure 9 , which present the investment in domestic and foreign assets by foreign and domestic (private) banks, respectively. While all banks increased their positions in foreign assets, the trend was substantially more pronounced among foreign banks. Moreover, domestic banks "financed" a larger fraction of their portfolio shift by reducing investments other than loans. This conclusion is confirmed in panel $\mathrm{C}$, which shows the paths of the 


\section{Figure 6. Additional Factors ${ }^{a}$}

A. Change in the stock of corporate debt and new equity

mill. US\$ Dec. 1998

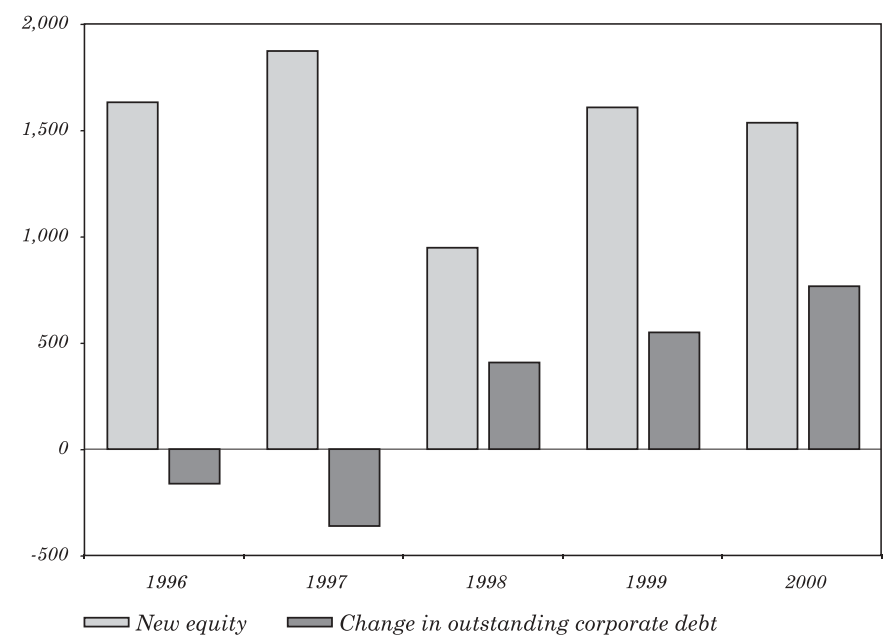

B. AFP holdings as fraction of GDP

Percent of GDP

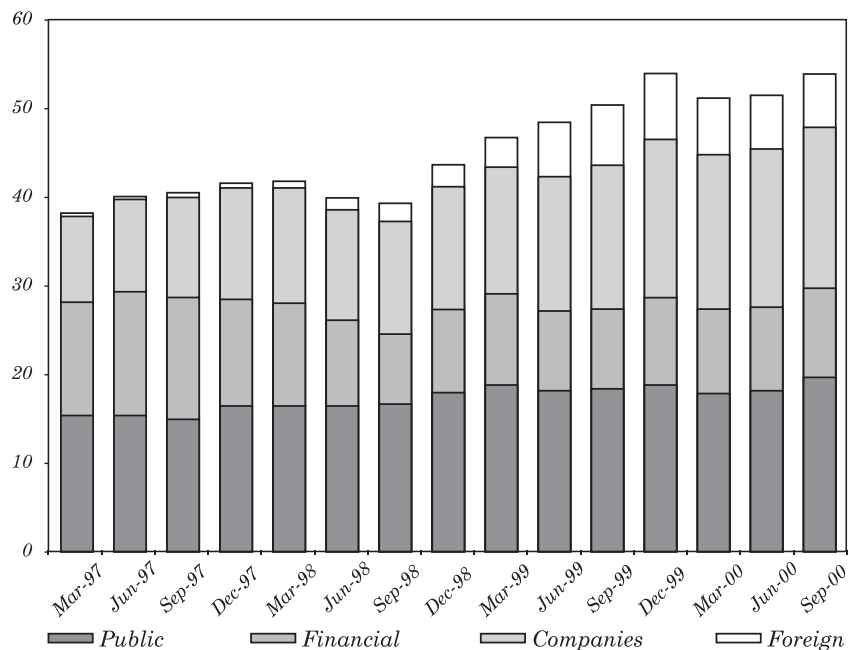

Source: Central Bank of Chile; Santiago Stock Exchange; Superintendencia de AFP; Superintendencia de Valores y Seguros.

In panel A, new equity is valued at issuance price and deflated using the consumer price index (CPI). The stock of corporate debt outstanding was also deflated by the CPI. The December 1998 exchange rate was 432 pesos per 
Figure 6. (continued)

\section{Retained eamings}

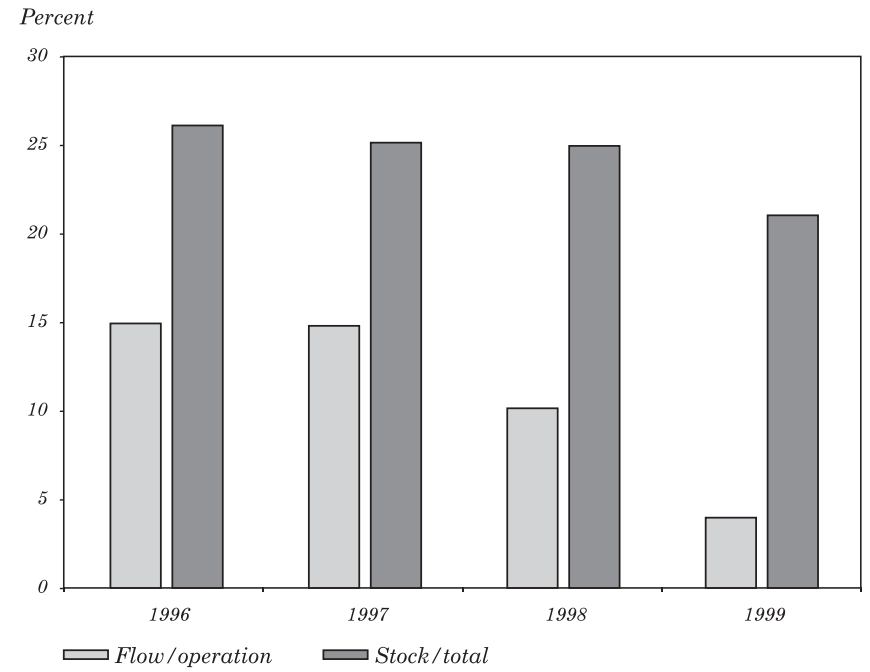

D. Labor share

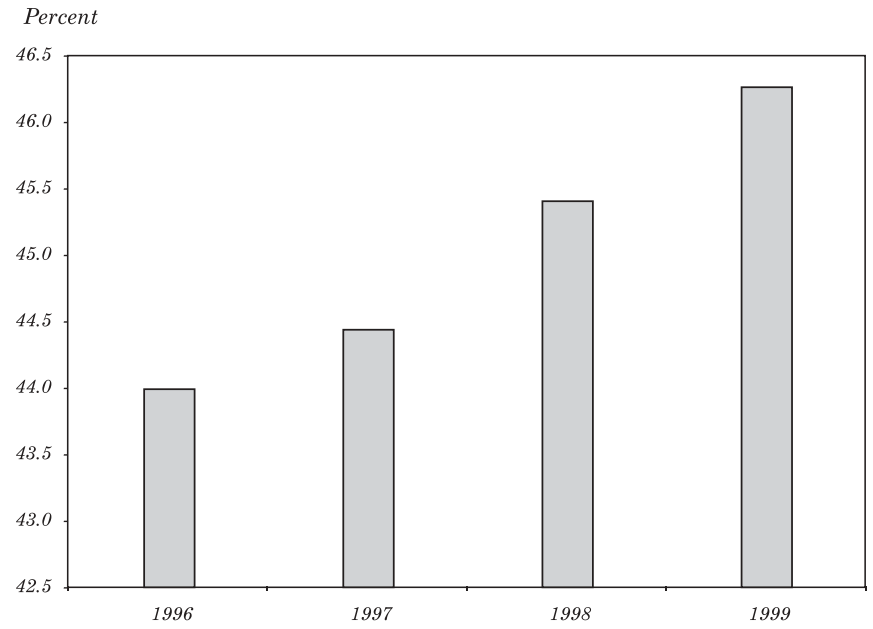

US dollar. In panel B, the values are expressed as a fraction of the year's GDP. In panel C, the data on retained earnings correspond to the stocks of retained earning reported in the balance sheets of all the companies traded in that exchange. They exclude investment firms, pension funds, and insurance companies. The flow value was computed as the difference in the (deflated) stocks at time $t$ and $t-1$. 


\section{Figure 7. The Credit Crunch ${ }^{\mathrm{a}}$}

\section{A. Loans and deposits of the banking system}

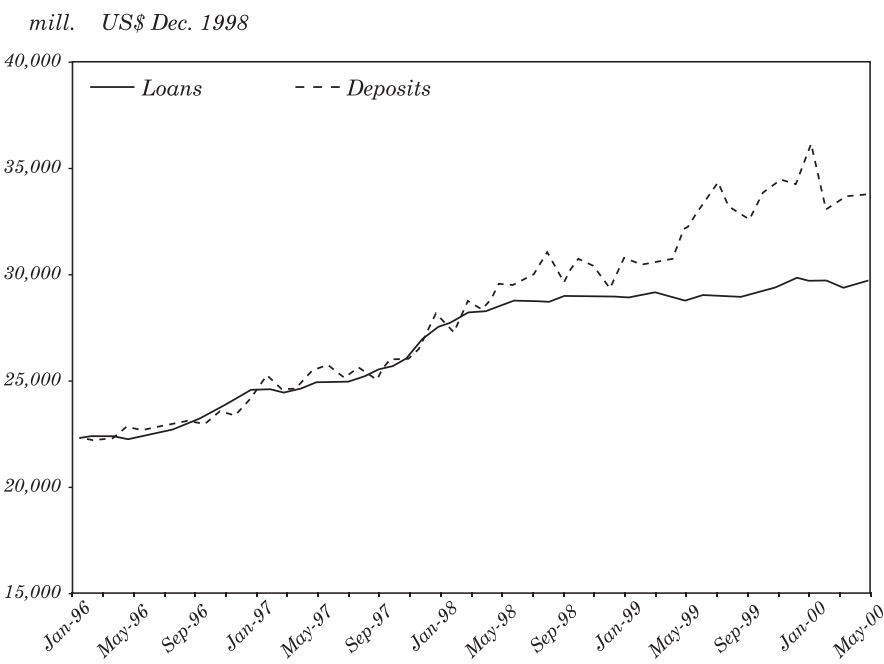

\section{B. Interest rate spreads (annual \%)}

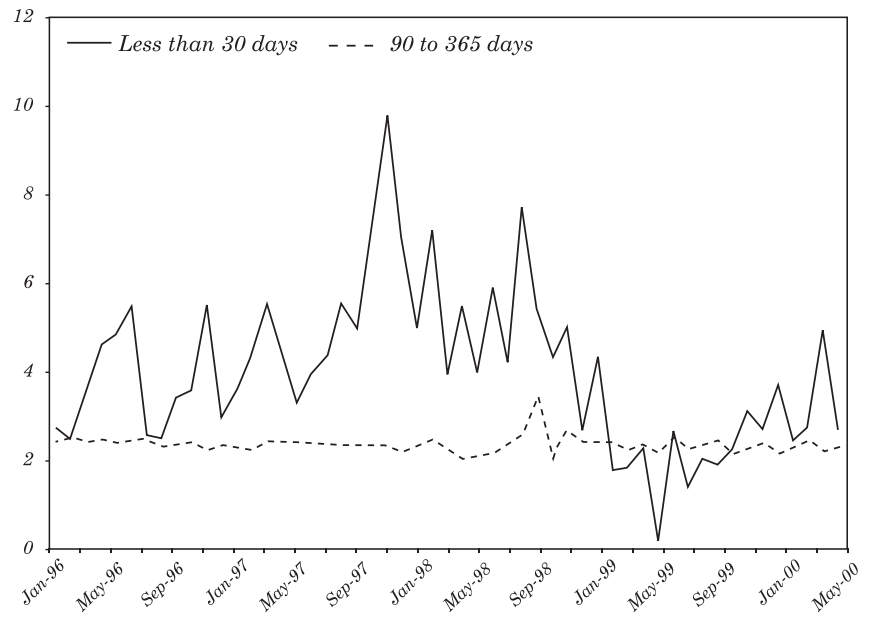

Source: Central Bank of Chile; Superintendencia de Valores y Seguros.

a. In panel A, loans include commercial, consumption, and trade loans and mortgages. Deposits include sight deposits and time deposits. The values are expressed in December 1998 dollars, using the average December 1998 exchange rate (472 pesos/dollar). In panel B, the thirty-day interest rates are nominal, while the ninety-day and one-year rates are real (to a first order, this distinction should not matter for spread calculations). 


\section{Figure 8. Capital Flows of the Banking System ${ }^{\text {a }}$}

A. Investment in domestic and external assets

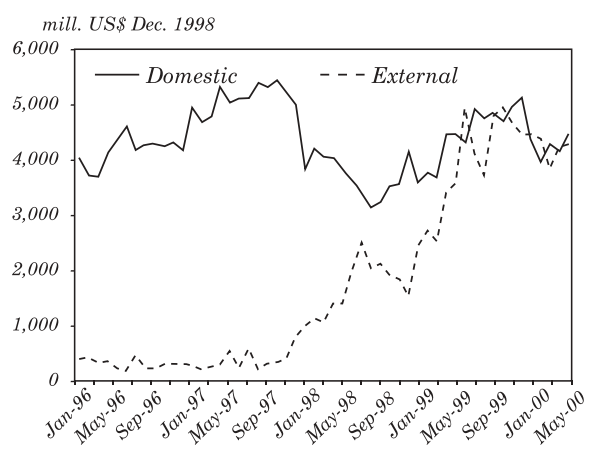

B. Net capital inflows

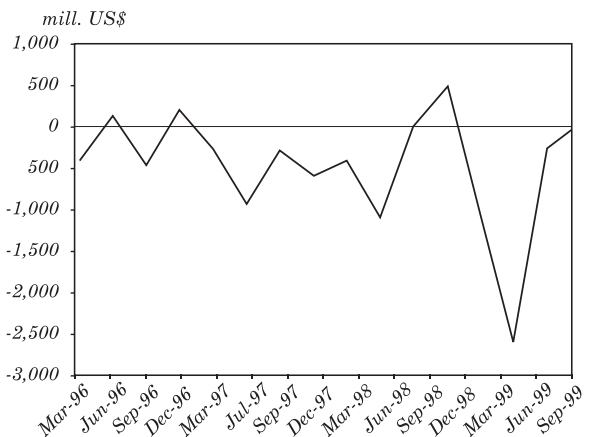

C. Composition of foreign assets

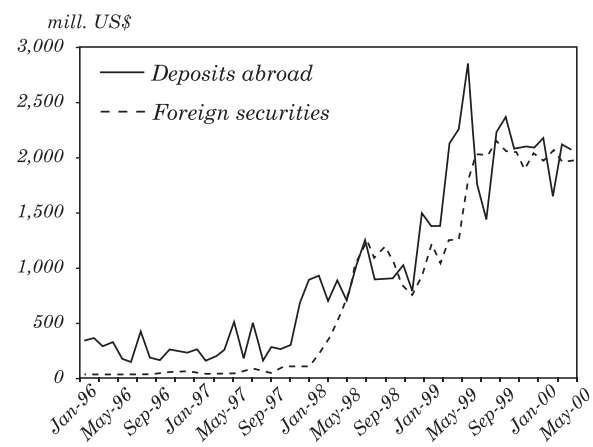

Source: Central Bank of Chile; Superintendencia de Bancos e Instituciones Financieras.

a. Domestic assets include Central Bank securities with secondary market and intermediated securities. External assets are the sum of deposits abroad and foreign securities. Deposits abroad are mostly sight deposits in foreign (nonresident) banks. Foreign securities are mostly foreign bonds. 


\section{Figure 9. Comparing Foreign and Domestic Bank Behavior ${ }^{\mathbf{a}}$}

A. Investment in domestic and external assets of foreign banks

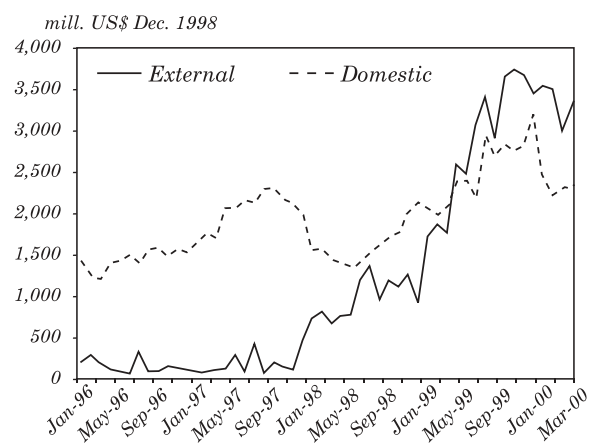

$B$. Investment in domestic and external assets of domestic banks

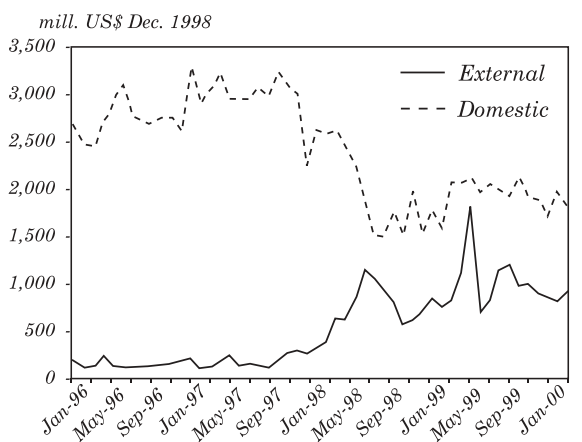

C. Loans over deposits of domestic and foreign banks except BHIF and Banco Santiago

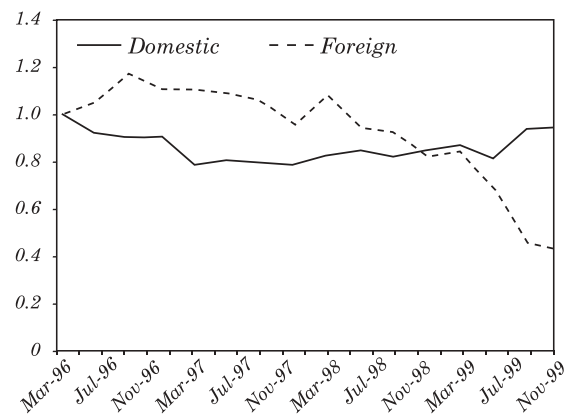

Source: Santiago Securities Exchange.

a. Domestic banks do not include Banco del Estado. Banco BHIF and Banco Santiago, which changed from domestic to foreign ownership during the period, were excluded from the sample. All constant 1998-peso series were converted to US dollars using the average exchange rate in December 1998 (472 pesos/dollar). Deposits include sight and time deposits. Loans include commercial, consumption, and trade loans, and mortgages. In panels A and B, domestic assets include Central Bank securities with secondary market and intermediated securities; external assets are the sum of deposits abroad and foreign securities. In panel C, loan-to-deposit ratios are normalized to one in March 1996. 
loans-to-deposit ratios of foreign (dashes) and domestic (solid) banks. ${ }^{12}$

The question arises whether factors other than nationality (such as the banks' risk characteristics) determined the differential response. While this is certainly a theme to be explored more thoroughly, the evidence in figure 10 suggests that this is not the case. Panel A shows that foreign banks did not experience a rise in net foreign currency liabilities that could account for additional hedging. They did not experience a significantly sharper rise in nonperforming loans than did domestic banks (panel B), and they were not affected by a tighter capital-adequacy constraint (panel C).

Foreign banks generally play many useful roles in emerging economies, but they do not seem to help smooth external shocks (at least in the most recent crisis). The credit and risk strategies of these banks are probably dictated from abroad, and there is no particular reason to expect them to behave too differently from other foreign investors during these times.

In summary, in 1999 - perhaps the worst full year of the crisis—banks reduced loan growth by approximately US $\$ 2$ billion. ${ }^{13}$ The increase in financial needs by the nonbanking private sector was about US $\$ 2$ billion, as well (see figure 5, panel C). Although these simple calculations ignore many general equilibrium issues, it is probably not too far-fetched to conclude that the financial crunch was extremely large, perhaps around US $\$ 4$ billion (about 5 to 6 percent of GDP) in that single year.

\section{The Costs}

The impact of the financial crunch on the economy is correspondingly large, especially on small and medium-sized firms.

12. This figure excludes two banks (Banco BHIF and Banco Santiago) that changed from domestic to foreign ownership during the period. The change in statistical classification took place in November 1998 for Banco BHIF and in July 1999 for Banco Santiago. In the case of Banco Santiago, the takeover operation by Banco Santander (the largest foreign bank in Chile) actually took place in May 1999. The Chilean bank regulatory agency (Superintendencia de Bancos) assumed that the two banks were going to merge and therefore ordered Banco Santiago to reduce its market presence. (The two banks had a joint presence equivalent to 29 percent of total loans.) The banks finally decided not to merge, and their joint market presence has remained unaltered thus far. The confusion created by the potential participation limits probably did not help the severe credit crunch that Chile was experiencing at the time.

13. A number close to US $\$ 2$ billion is obtained from the difference between the flow of loans during 1999 (computed as the change in the stock of loans between December 1999 and December 1998) and the flow of loans in 1996 (computed in a similar manner). 


\section{Figure 10. Risk Characteristics of Foreign and Domestic}

Banks $^{\mathbf{a}}$

A. Foreign currency assets and liabilities: foreign banks

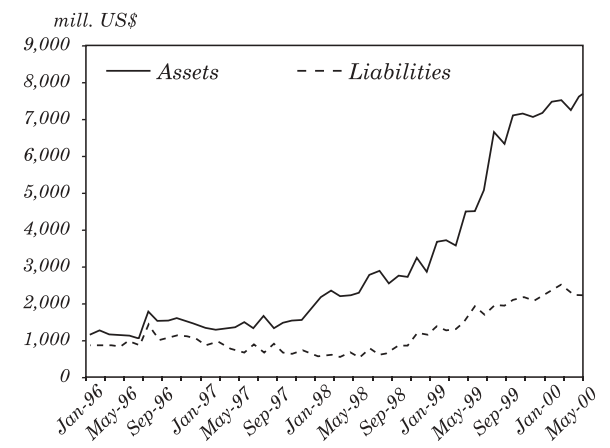

B. Non performing loans as percentage of total loans:

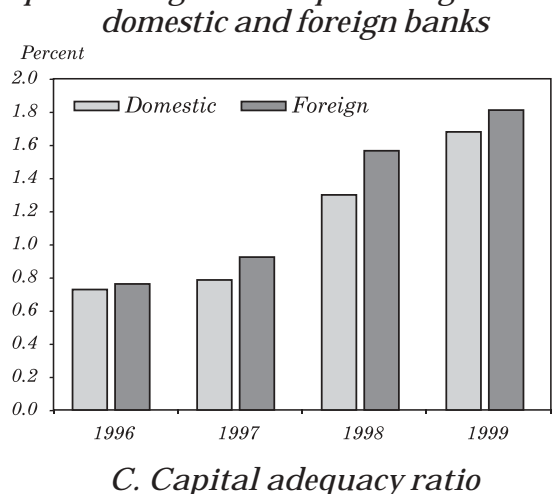

C. Capital adequacy ratio

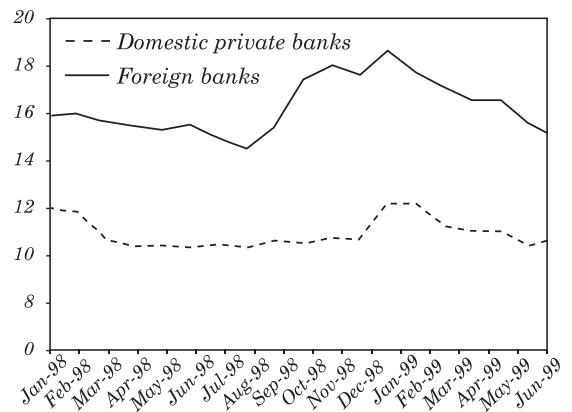

Source: Superintendencia de Bancos e Instituciones Financieras.

a. In panel A, foreign assets include foreign loans, deposits abroad, and foreign securities. Foreign liabilities include funds borrowed from abroad and deposits in foreign currency. In panel B, ROE is the ratio of total profits over capital and reserves (as a percentage). Domestic private banks do not include Banco del Estado. 


\subsection{The Aggregates}

Figure 2 summarized the first-order impact of the financial mechanism, with a domestic business cycle that is many times more volatile than it would be if financial markets were perfect. This excess volatility was particularly pronounced in the recent slowdown, as illustrated by panel A in figure 11. National income and domestic demand not only appear to move together, but the latter adjusts more than the former, implying that the largely transitory terms-of-trade shock is not being smoothed over time. Panel B illustrates a sharp rise in the unemployment rate that has yet to be reversed.

Aside from the direct negative impact of the slowdown and any additional uncertainty that may have been created by the untimely discussion of a new labor code, the buildup in unemployment and its persistence can be linked to two aspects of the financial mechanism described above. First, in the presence of an external financial constraint, the real exchange rate needs a larger adjustment for any given decline in the terms of trade. ${ }^{14}$ Consequently, a big share of the adjustment falls on the labor-intensive nontradables sector, as illustrated in panel A of figure 12. Second, going beyond the crisis and into the recovery, the lack of financial resources hampers job creation, a phenomenon that is particularly acute among SMEs. While I do not have data on job creation, panel $B$ shows that investment suffered a deeper and more prolonged recession than the rest of domestic aggregate demand. This is important beyond its impact on unemployment, as it also hints at the slowdown of one of the main engines of productivity growth: the restructuring process. If the United States is any indication of the costs associated with this slowdown in restructuring-possibly a very optimistic lower bound for the Chilean costs - this mechanism may add a significant productivity loss amounting to over 30 percent of the employment cost of the recession. ${ }^{15}$

As the external constraint tightens, all domestic assets that are not part of international liquidity must lose value sharply to offer significant excess returns to the few agents with the will and liquidity to buy them. Panel A of figure 13 shows a clear trace of this V-pattern in the Chilean stock market. Panel B is perhaps more interesting, as it illustrates that foreign direct investment (FDI) increased by almost

14. The larger real exchange rate adjustment corresponds to the dual of the financial constraint. See Caballero and Krishnamurthy (2001c).

15. See Caballero and Hammour (1998). 


\section{Figure 11. Output, Demand, and Unemployment ${ }^{\text {a }}$}

A. Domestic demand and national income
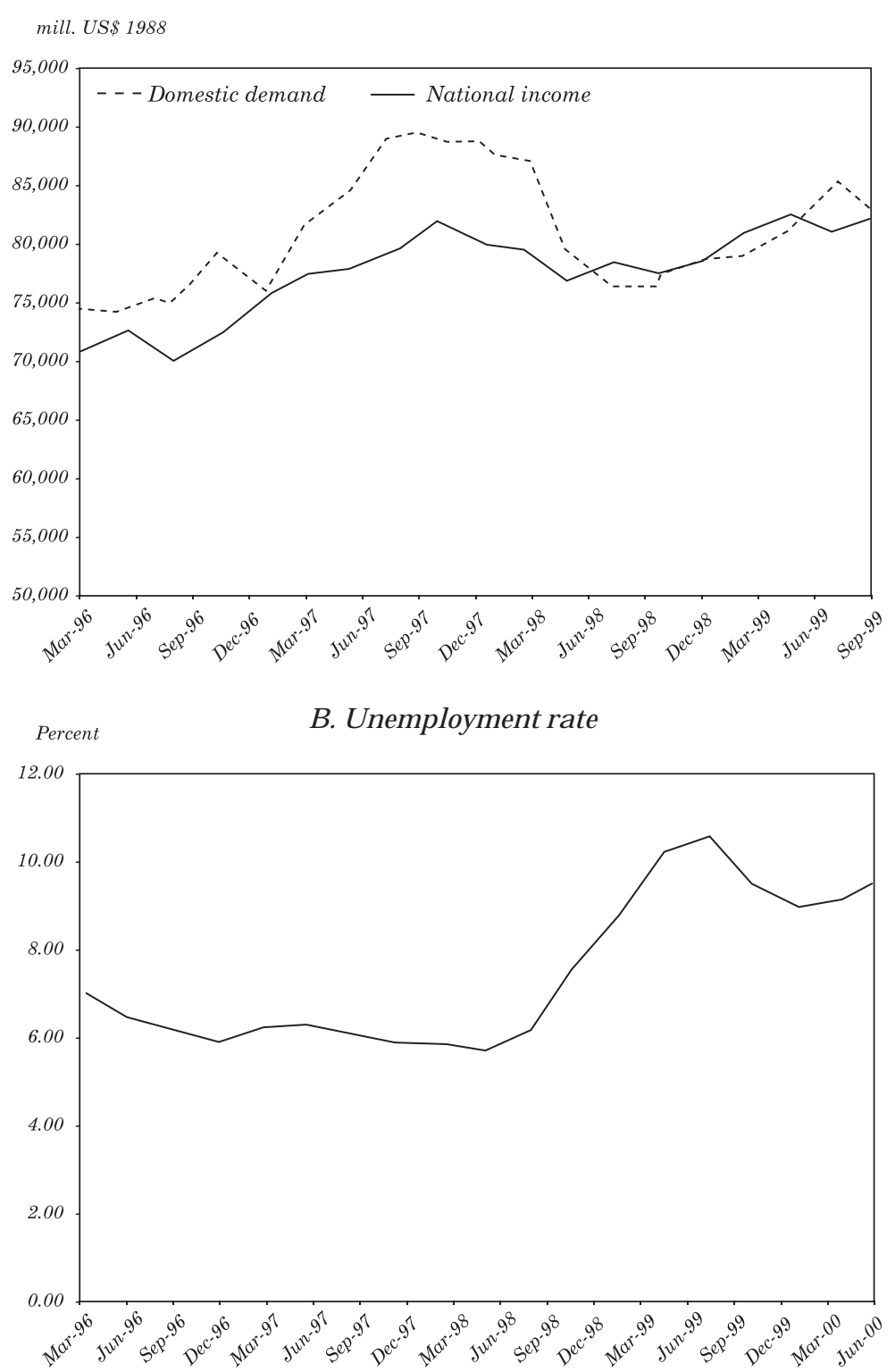

Source: Central Bank of Chile; National Bureau of Statistics (INE).

a. Series are seasonally adjusted and annualized. 


\section{Figure 12. Forced and Depressed Restructuring ${ }^{a}$}

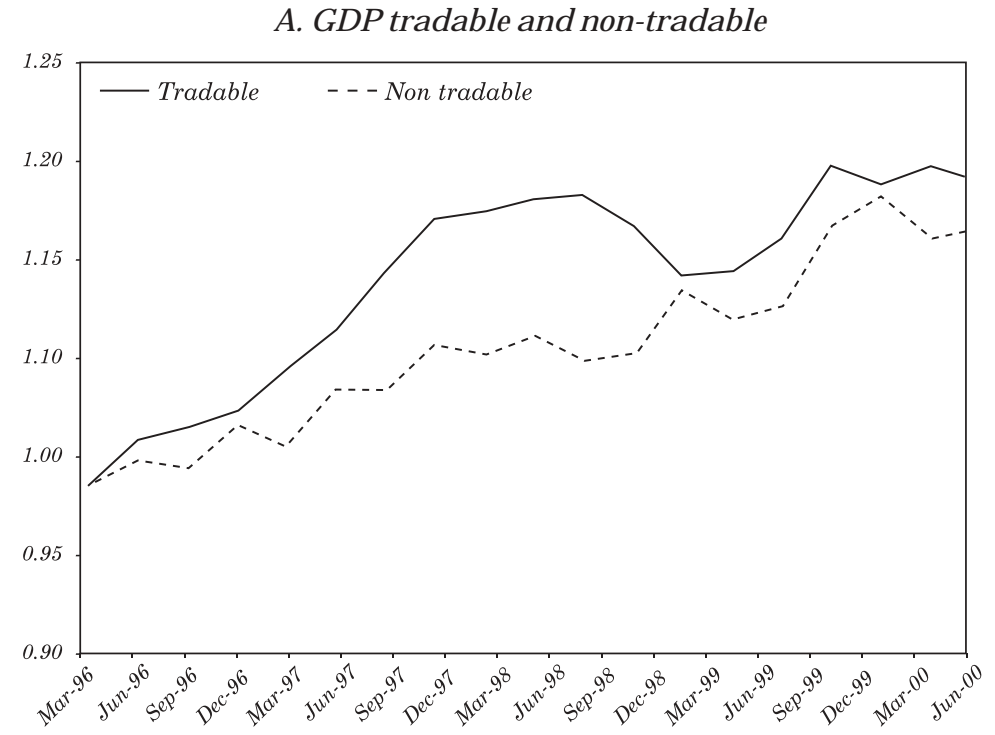

\section{B. Evolution of domestic demand}

mill US\$1998

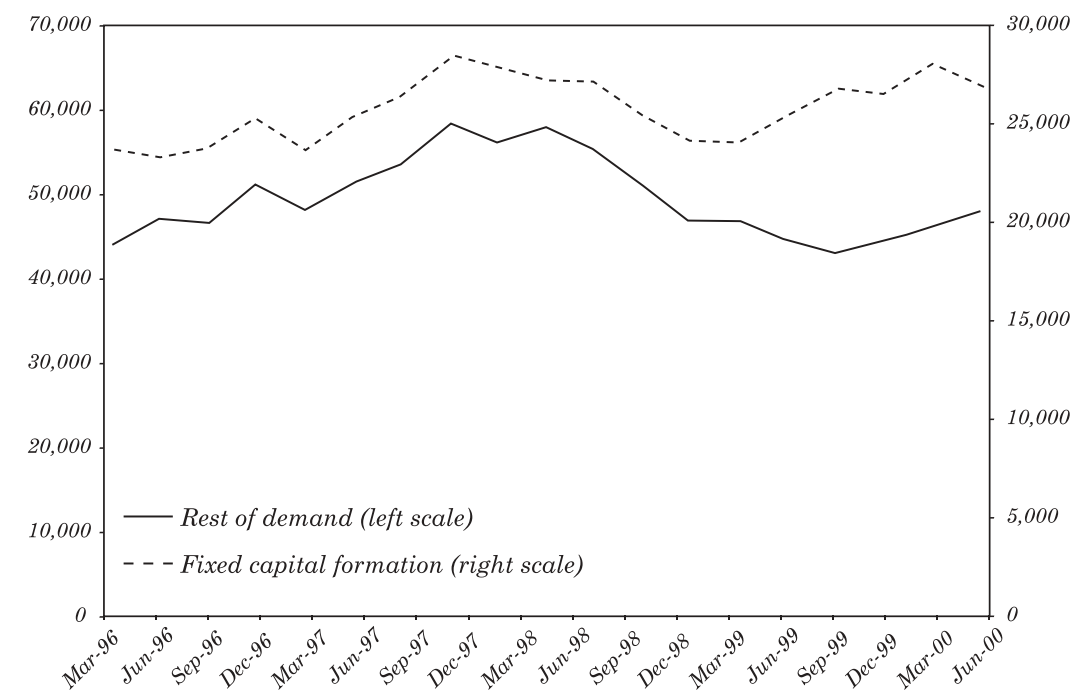

Source: Central Bank of Chile.

a. Series are seasonally adjusted and normalized to one in March 1996. The tradables sector includes agriculture, fishing, mining, and manufacturing; the nontradables sector includes electricity, gas and water, construction, commerce, transport and telecommunications, and other services. 
US $\$ 4.5$ billion in 1999 and created a bottom to the fire sale of domestic assets. However, while FDI is very useful in that it provides external resources when they are most scarce, its presence during the crisis also reflects the severe costs of the external financial constraint, as valuable assets are sold at heavy discounts.

\subsection{The Asymmetries}

The real consequences of the external shocks and the financial amplification mechanism are felt differently across firms of different sizes. Large firms are directly affected by the external shock, but they can substitute their financial needs domestically. They are affected primarily by price and demand factors. SMEs, on the other hand, are crowded out of domestic financial markets and thus become severely constrained financially. They are the residual claimants of the financial dimension of the mechanism described above, as are indebted consumers to a lesser extent.

Figure 14 illustrates some aspects of this asymmetry. First, panel A shows the path of the share of large loans as an imperfect proxy for resident bank loans going to large firms. Next, panel B, shows a sharp increase in the relative size of large loans. The two trends together hint at a substantial reallocation of domestic loans toward relatively large firms. In the policy section below, I argue that some of this reallocation is likely to be socially inefficient.

The next figure looks at relatively large, publicly traded firms. ${ }^{16}$ The figure points to important differences between the largest of them and the medium-sized ones. A comparison of the paths of medium-sized and large firms' bank liabilities (normalized by initial assets) during the recent slowdown indicates that larger firms fared better than medium-sized companies, which saw their level of loans frozen throughout 1999. Perhaps more importantly, since the sum of loans to medium-sized and large firms rose while total loans declined throughout the crisis, the contraction must have been particularly significant among smaller firms (not shown in the figure).

16. The firms included in Figure 15 are drawn from the Ficha Estadística Codificada Uniforme (FECU), which is the standardized balance sheet that every public firm in Chile is required to file quarterly with the supervisory authority (the Superintendencia de Valores y Seguros). The database contains information on those standardized balance sheets for every public firm reporting to the authority between the first quarter of 1996 and the first quarter of 2000. 


\section{Figure 13. Fire Sales}

A. Value of Chilean stocks (IGPA index $)^{a}$

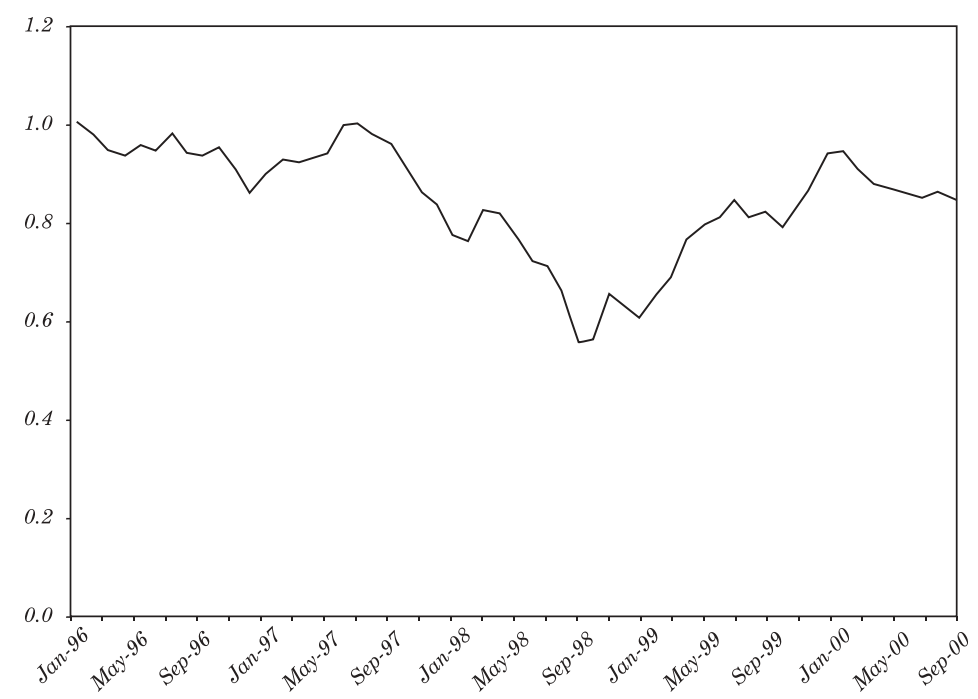

B. Foreign direct investment (FDI)

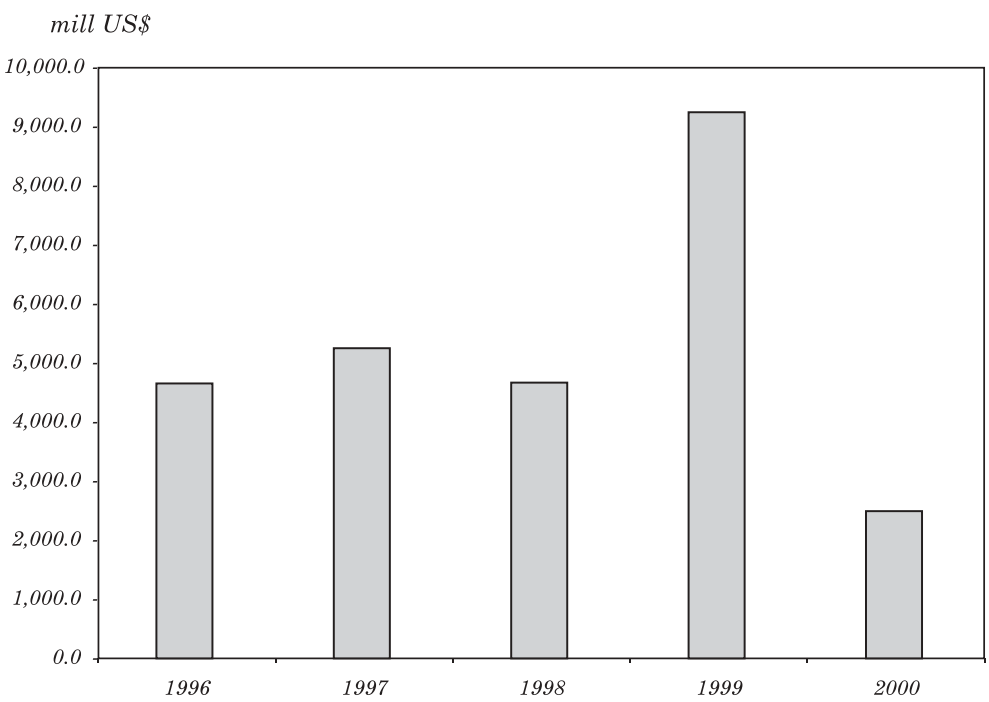

Sources: Central Bank of Chile and Bloomberg.

a. The IGPA is the general stock price index of the Santiago Stock Exchange. 


\section{Figure 14. Flight to Quality ${ }^{a}$}

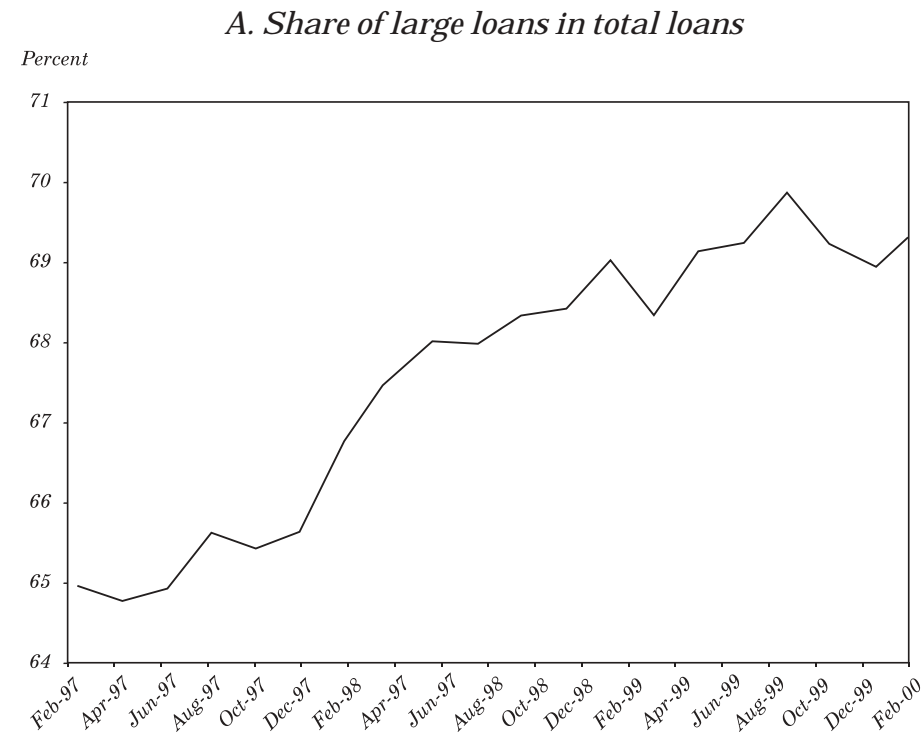

\section{B. Average size of small and large loans}

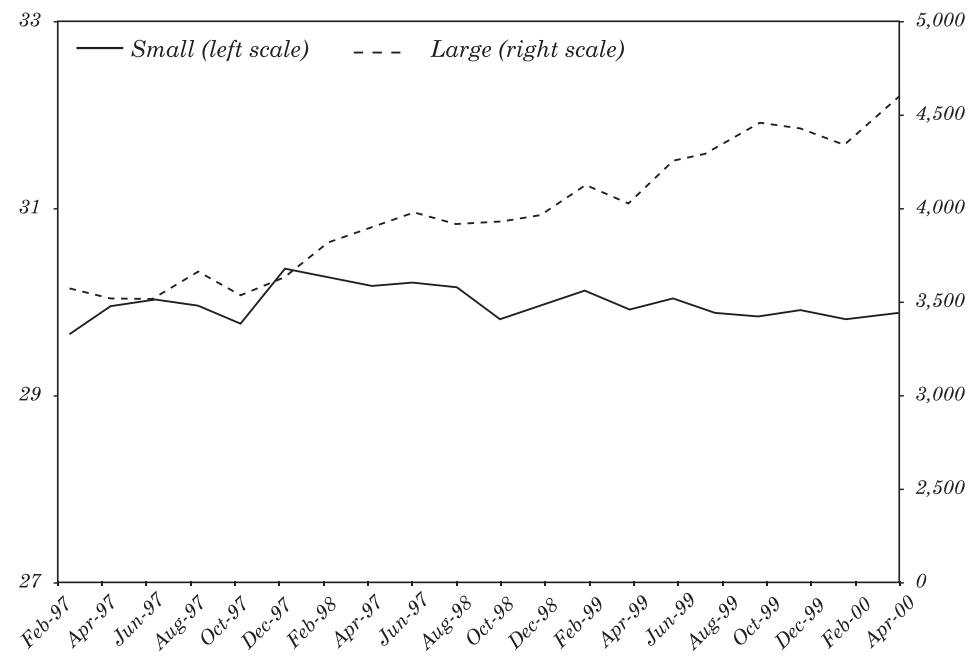

Source: Superintendencia de Bancos e Instituciones Financieras.

a. Large loans: over 50,000 UF (about US $\$ 1.4$ million in 1999 dollars); small loans: between 400 UF (US $\$ 11,000$ )

and 10,000 UF (US $\$ 280,000$ ). In panel B, the average size corresponds to the stock of loans in each class divided by the number of debtors. 


\section{Figure 15. Bank Debt of Publicly Traded Firms, By Size}

\section{A. Bank liabilities of medium and large firms}

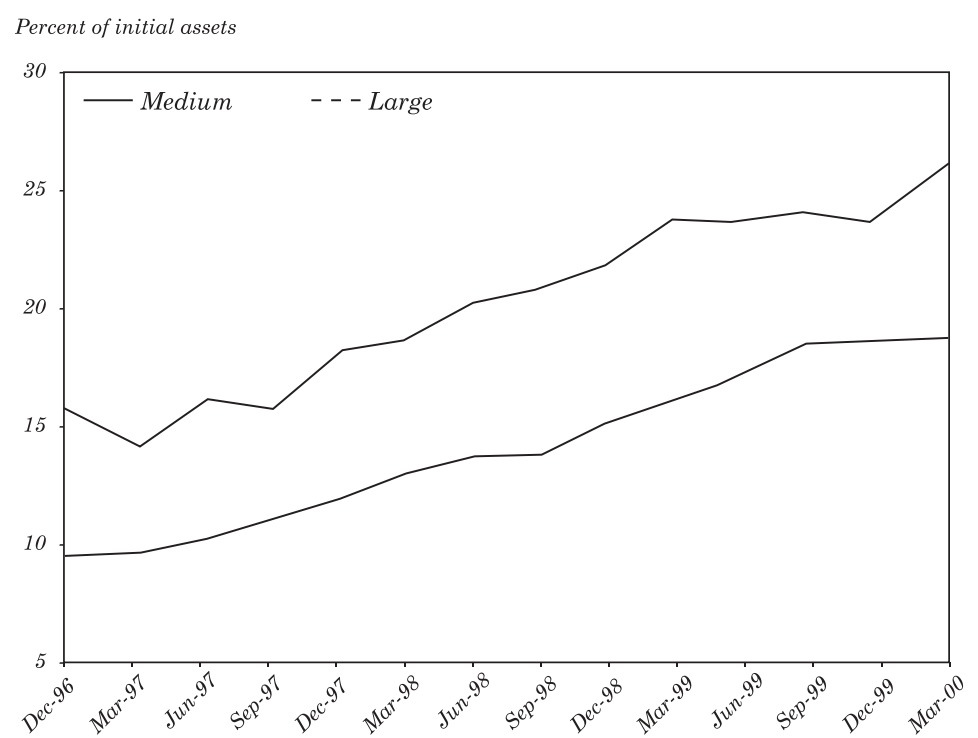

Source: Author's calculations, based on data from the standard form Ficha Estadistica Codificada Uniforme (FECU), Superintendence of Securities and Insurance.

a. The sample includes all firms that continuously reported information between December 1996 and March 2000. Within this sample, the medium-sized firms (thus termed since they are larger than firms outside the sample) are those with total assets below the median level of total assets in December 1996. The series correspond to the total stock of bank liabilities at all maturities expressed in 1996 pesos, divided by the total level of assets in December 1996. The nominal values were deflated using the CPI. The total level of assets in December 1996 was US $\$ 788$ million for the group of medium-sized firms and US\$59.3 billion for the group of large firms.

The Chilean economy is thus still very vulnerable to external shocks despite significant institutional development over the last two decades. The main reason for this vulnerability appears to be a double-edged financial mechanism, which includes a sharp tightening of Chile's access to international financial markets and a significant reallocation of resources from the domestic financial system toward larger corporations, public bonds, and, most significantly, foreign assets.

\section{Policy Considerations and a Proposal}

The previous diagnostic points at the occasional tightening of an external financial constraint-especially when the terms of trade deteriorate-as the trigger for the costly financial mechanism. 


\subsection{General Policy Considerations}

If the above assessment is correct, it calls for a structural solution based on two building blocks: measures aimed at improving Chile's integration to international financial markets and the development of domestic financial markets, and measures aimed at improving the allocation of financial resources in times of external distress and across states of nature. The first set of measures is already broadly understood, at least as an objective, and Chile is making significant progress along this dimension through its capital markets reform program. I therefore focus on the second group as the guiding principle of the policy discussion below. That is, I focus primarily on the international liquidity management problem raised by the above analysis. ${ }^{17}$

International liquidity management is primarily an insurance problem with respect to those (aggregate) shocks that trigger external crises. Solutions to this problem must have a contingent nature. The first step is to identify a set of shocks that captures a large share of the triggers to the mechanism described above. In the case of Chile, the terms of trade, J.P. Morgan Latin American Emerging Markets Bond Index Plus (Latin EMBI+), and weather variables represent a good starting point. The particular index chosen, however, is a central aspect of the design, and it needs to be extensively explored before it is implemented.

The second step is to identify desirable ex post transfers (perhaps temporary loans rather than outright transfers). Broadly speaking, these are simply transfers from foreign to domestic agents and from less constrained domestic agents to more constrained ones. In practice, however, the needs and availability of agents are greatly heterogeneous, which raises information requirements considerably. It is thus highly desirable to let the private sector take over the bulk of the solution, which begs the question of why this sector is not already doing as much as is needed. The answer to this question should identify the policy goals with the highest returns.

The most likely explanations can be grouped into two categories: supply and demand factors. At least three supply factors figure prominently.

Coordination problems. These arise from the absence of a welldefined benchmark around which the market can be organized.

17. See Caballero $(1999,2001)$ for general policy recommendations for the Chilean economy, including recommendations on the first set of measures. My objective in the current paper is instead to focus on and deepen the discussion of a subset of those policies and to add an implementation dimension. 
Limited insurance capital. This situation may stem from either structural shortages or a financial constraint (in the sense that what is missing is assets that can be credibly pledged by the "insurer," rather than actual funds during a crisis). A closely related problem, but with coordination aspects as well, is that the liquidity and collateral risks faced by the insurers increase when the market encompasses an insufficient number of participants.

Sovereign (dual-agency) problems. Although contracts are signed by private parties, government actions affect the payoffs of these contracts. ${ }^{18}$

Demand factors, in turn, also account for at least three sources of underinsurance.

Financial underdevelopment. This leads to a private undervaluation of insurance with respect to aggregate shocks, which depresses effective competition for domestically available external liquidity at times of crises and reduces the private (but not the social) valuation of international liquidity. ${ }^{19}$

Sovereign problems. The government may provide explicit or implicit insurance to the private sector.

Behavioral problems. Overly optimistic market participants undervalue the need for insurance.

Domestic financial underdevelopment is still a problem in Chile. The solution to this problem should be pursued primarily through financial market reform. In the meantime, however, an adequate use of monetary and reserves management policy may remedy some of the underinsurance implications of this deficiency. I briefly discuss the general features of this policy in the next section. A more extensive discussion can be found in Caballero and Krishnamurthy (2001a).

At the same time, behavioral problems seem to be a pervasive human phenomenon (see, for example, Shiller, 1993). The macroeconomic implications of this factor can partly be remedied through the same mechanisms designed to address financial underdevelopment. Great care must be taken, however, not to generate a sizeable sovereign-insurance problem, which is otherwise not likely to be present in any significant amount in the case of Chile (and nor are dual-agency problems).

This process of elimination leaves coordination problems as the main focus of my policy proposal, which is discussed extensively in section 3.3.

18. See, for example, Tirole (2000).

19. See Caballero and Krishnamurthy (2001b, 2001c). 
Figure 16. External Crisis

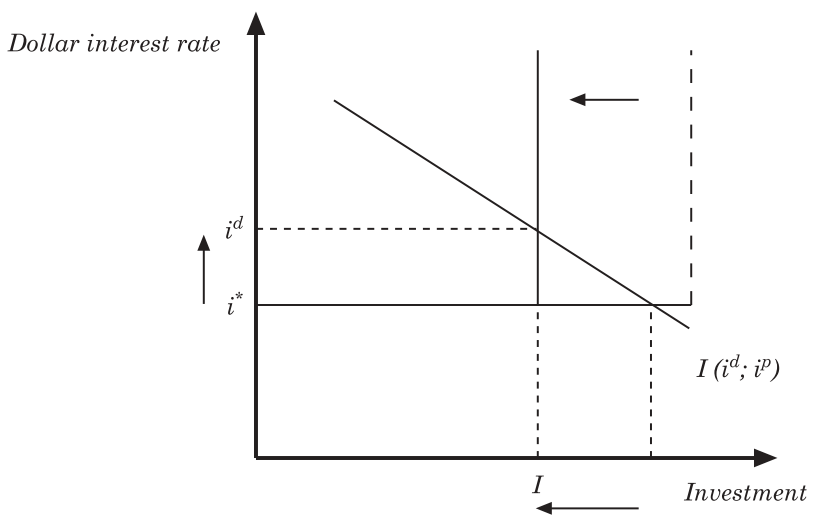

\subsection{Monetary Policy as a Solution to the Underinsurance Problem}

Figure 16 provides a stylized characterization of an external crises of the sort described above. The main problem during an emerging market crisis is well captured by the presence of a vertical external constraint. That is, external crises occur when it becomes very difficult, at the margin, for most domestic agents to gain access to international financial markets at any price. Consequently, international liquidity becomes scarce, and domestic competition for these resources bid up the dollar cost of capital, $i^{d}$, over the international interest rate faced by prime (international) Chilean assets, $i^{*}$. The dual of this crunch is a sharp fall in investment.

A few aspects of this perspective of a crisis have caused some confusion in the past. First, particularly in the case of Chile, the rise in the sovereign (or prime firms') spread is not a measure of the rise in the domestic (shadow or observed) rate, $i^{d}$; rather, it represents the rise in $i^{*}$, which in turn may tighten the vertical constraint.

Second, the country does not need to literally run out of international liquidity for the vertical constraint to bind for small and lessthan-prime firms. In fact, total scarcity is seldom the case in Chile. If prime firms, banks, and the government perceive that there is a significant chance of a severe external crisis in the future, they may de- 
cide to hoard international liquidity rather than lend it domestically, even when the current domestic spread $\left(i^{d}-i^{*}\right)$ is positive.

Finally, the constraint is seldom completely vertical in practice. The logic of the analysis that follows must therefore be blended with a standard Mundell-Fleming analysis. The interesting new insight, however, is still that which is related to the nonflat aspect of the supply of funds. ${ }^{20}$

\section{Ex Post Optimal Monetary and Reserves Policy during a Crisis}

Before discussing optimal policy from an insurance perspective, it is worth highlighting the incentives that a central bank faces during an external crisis. The main shortage experienced by the country is one of international liquidity (or collateral, broadly understood). Thus, an injection of international reserves into the market is a very powerful tool: it directly relaxes the vertical constraint on investment in figure 16, and it stabilizes the exchange rate. During an external crisis, international arbitrage does not hold because there is an external credit constraint. Domestic arbitrage, on the other hand, must hold. Peso and dollar instruments backed by domestic collateral must yield the same expected return (risk aversion aside). The domestic arbitrage condition is thus

$i^{d}=i^{p}+(e-E e)$,

where $i^{p}$ denotes the peso interest rate, $e$ the (logarithm of the) current exchange rate, and $E e$ the expected interest rate for the next period. In what follows, I take the latter as given, although interesting interactions arise when this expectation is affected by policy (see Caballero and Krishnamurthy 2001a).

Rearranging equation 1 yields an expression for the exchange rate:

$e-E e=i^{d}-i^{p}$

which shows that as $i^{d}$ falls with the injection of reserves, the exchange rate appreciates for any given peso interest rate.

20. Part of the explanation of the diagonal shape, in practice, is that the currency depreciates as $i^{d}$ rises. If exports are an important dimension of the country's international liquidity, then a depreciation increases international collateral. 
The effectiveness of reserve injections in boosting investment and protecting the exchange rate contrasts sharply with the impact of an expansionary monetary policy. The main problem during an external crisis is the lack of international-rather than domestic-liquidity. Domestic liquidity facilitates domestic loans; hence the role of $i^{p}$ in the investment function in figure 16 (given $i^{d}$, lower peso interest rates raise investment demand). Domestic liquidity does not, however, relax the binding international financial constraint, to a first order. Consequently, an expansionary monetary policy is not effective in boosting real investment in equilibrium. Its main impact is, instead, to raise domestic competition for the limited international liquidity; hence $i^{d}$. By equation 2, this means that the exchange rate depreciates sharply, as it must not only offset the reduction in $i^{p}$ (the standard channel), but also absorb the rise in $i^{d}$.

A central bank that has an inflation target and that is concerned with the impact of the exchange rate on that target will thus prefer to tighten monetary policy. Doing otherwise does not have much real benefit during a crisis, and it can lead to a sharp exchange rate depreciation.

\section{Ex Ante Optimal Monetary and Reserves Policy during Crisis}

If the central bank could commit to a monetary policy ex ante, would it still choose to tighten during a crisis? The answer is no. The primary problem is the private sector's underinsurance with respect to aggregate external shocks. The amount of international liquidity that the country has during an external crisis may be exogenous at the time of the crisis, but it is not exogenous ex ante. It depends on several factors, including how much international borrowing occurred during the boom years, the maturity structure and denomination of that debt, the contingent credit lines contracted, and the sectoral allocation of investment. Underinsurance means that these decisions did not fully internalize the social cost of sacrificing a unit of international liquidity. Figure 17 captures this gap by adding a social valuation curve to figure 16. The gap $\Delta-i^{d}$ captures the undervaluation problem. In other words, if the private sector's expected value of a unit of liquidity had been $\Delta$ as opposed to $i^{d}$, then private investors would have hoarded more international liquidity and the vertical constraint during the crisis would have shifted to the right.

Thus, while an expansionary monetary policy during a crisis is unable to boost investment, the anticipation thereof is. If private agents 


\section{Figure 17. Underinsurance}

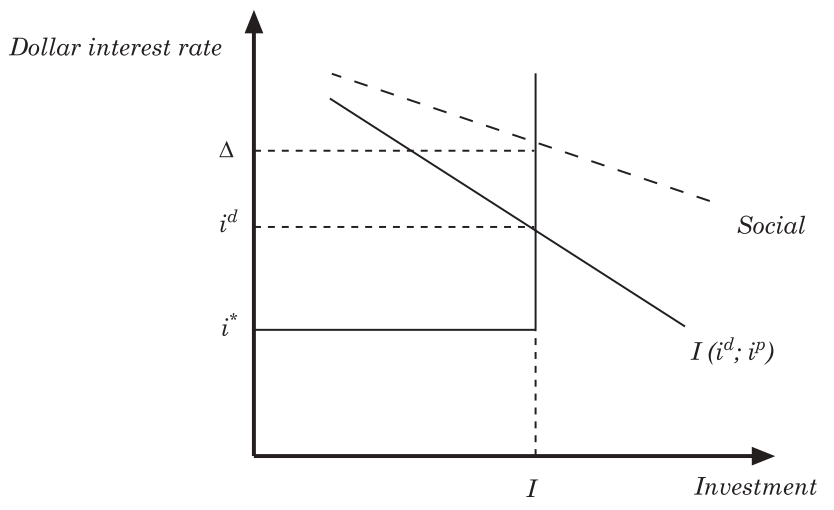

anticipate such a policy, they will expect a higher $i^{d}$ and hence will make ex ante decision more in line with those of the social planner. In this context, the main role of monetary policy is one of incentives rather than one of liquidity provision.

What about international reserve injections? They are still optimal ex ante, but the fall in $i^{d}$ they bring about has a perverse incentive effect that also needs to be offset by the expansionary monetary policy.

Before concluding this section, I mention two caveats. First, a related but distinct type of monetary policy ineffectiveness arises during the recovery phase of an external crunch. While international liquidity may no longer be the binding constraint in this phase, a new constraint arises in the form of the lack of domestic collateral among SMEs-lost during the international crunch. An expansionary monetary policy in this case injects resources into the banking system, but it does not reach SMEs, since the binding constraint is not the availability of loanable funds.

Second, I have taken $E e$ as given throughout. If this is not warranted, in the sense that the commitment to a post-crisis inflation target is not sufficiently credible and is seriously compromised by policies during the external crunch, then monetary policy may not be an available incentive mechanism. Having lost the latter, the authorities may have to resort to much costlier incentive mechanisms such as capital controls. This is not the case in Chile today. 


\subsection{Creating a Market: Issuing a Benchmark- Contingent Instrument}

As mentioned above, another key factor behind underinsurance is simply a coordination problem. While there are many ways to hedge and to hoard international liquidity, they tend to be cumbersome and costly for most, especially when the goal is to obtain long-term insurance. The basic proposal here is extremely simple: the Central Bank or, preferably, one of the international financial institutions should issue a financial instrument-a bond, for now-that is contingent on the shocks identified in step one in section 3.1. Ideally, this bond should be free of other risks and thus should be underwritten by a reputable first issuer. The issue should be significant enough to attract the participation of international institutional investors, which would generate its liquidity. Some of the desired insurance will be achieved directly by this bond, but its main purpose is simply to create the market. With the basic contingency well priced, the private sector will find it substantially simpler to engineer its own contingent instruments.

The contingency generated via this mechanism addresses only the expected differential impact of the aggregate shocks contained in the index. Individual agents will generate heterogeneity in their effective hedging through their net positions rather than through a change in the specific contingency. ${ }^{21}$ Other, more idiosyncratic underinsurance problems are also welfare reducing, but they are less connected with aggregate stabilization, which is the concern of this paper. ${ }^{22}$

In principle, the question of how responsive the contingency should be to the underlying insurance factors or indexes is irrelevant, since the private sector should be able to develop the derivative markets that can generate any slope they may need. In practice, however, financial constraints and liquidity considerations suggest otherwise. The bond contingency should therefore be very steep, so as to minimize the leverage and derivative instruments required to generate an appropriate amount of insurance for large crises. The counterpart will probably be

21. See Shiller's (1993) seminal work on promoting the creation of macromarkets as a mechanism for insuring microeconomic risks. While much of his reasoning also applies in the context I discuss, my ultimate focus is on the equilibrium (macroeconomic) benefits of microeconomic insurance with respect to macroeconomic shocks, rather than on the direct microeconomic welfare-enhancing features of such insurance.

22. Insurance against aggregate shocks is also more likely to support a market instrument as its solution, as opposed to more expensive (less liquid) individually tailored insurance contracts. 
a very limited insurance against small and intermediate shocks, which should be fine since these shocks seldom trigger the financial amplification mechanism highlighted in this paper.

How much insurance does a country need? This question is not easy to answer because it involves many general equilibrium considerations. Even so, a very conservative answer for a full-insurance upper bound should not be very far from the partial equilibrium answer. Crises deep enough to trigger the complex scenarios recently experienced by Chile are probably once-in-a-decade events; the estimates presented earlier on the shortfall of resources indicate that they probably involve about US $\$ 5$ billion a year and last for at most two years. (Longer recessions probably stem from the damage created by the lack of insurance, rather than the direct effect of the external shocks.) The required insurance is only a fraction of this shortfall, however, since these resources need only be lent, not transferred. If I conservatively assume that the average (shadow, not sovereign) spread on Chilean external debt rises by 600 basis points, then the required insurance is effectively US $\$ 300$ million per crisis year (with the loan commitment or credit line). Combining all these factors puts the fair price of full insurance at around US\$60 million a year. Of course, prices for this type of insurance are never fair, but the point of this back-of-the-envelope calculation is that the amounts involved are not large.

Mapping the above onto the size of the contingent bond issues required depends on the slope of the contingency, the amount of insurance required (full insurance is highly unlikely to be optimal), and other design issues. The benchmark bond should represent only a small fraction of the total amount, since the private sector should follow suit. The issue cannot be too small, however, since it needs to be liquid enough from the outset.

The above discussion refers to the insurance between foreign and domestic agents, but a substantial amount of domestic insurance is also needed. Large corporations with better access to international financial markets should be able to profit from arbitraging their access to smaller domestic firms, rather than moving inward to borrow in the domestic markets during time of distress, as happened in the recent episode. The domestic banking system is probably the natural institution for administering this side of the contingent strategy, which would probably require regulatory changes to accommodate this new role without causing undesirable domestic credit crunches as the index moves around.

The question arises of whether the development of such contingency has any obvious advantage over the admittedly simpler strategy 
of internationalizing the peso-that is, of placing abroad bonds denominated in Chilean pesos. The Central Bank is currently pursuing this strategy with the support of a recent World Bank issuance of US $\$ 105$ million in peso-denominated bonds. ${ }^{23}$ These bonds serve a role similar to that of the contingent instruments I propose in that the shocks indexing the contingency will in all likelihood put pressure on the exchange rate, but they have a clear disadvantage: because the Chilean authorities largely control the value of the peso, this contingency is unlikely to appeal to the insurers (or bond holders) as much as an exogenous contingency would. Moreover, and somewhat paradoxically, a peso-denominated bond may not only be subject to a higher premium owing to the risk of the Central Bank's manipulation of the exchange rate, but it may also prove to be a not very effective insurance mechanism if, for example, the authorities decide to dampen an exchange rate depreciation that is putting an inflation target at risk. ${ }^{24}$

The disadvantage of the contingent bond, on the other hand, is that it is more difficult to implement, and the risk of not finding a market for it is thus nonnegligible. It will require careful planning to design an instrument that it is not difficult to comprehend and whose contingencies are fully transparent. The experiences of previous placements of commodity-indexed bonds should be studied carefully. Although bonds with warrants on the issuer's shares have become fairly common financial instruments, bonds embedded with options on commodity prices are still relatively rare. These commodity-indexed bonds have generally been attractive to investors who would like to participate in commodity options but cannot purchase directly for regulatory or other reasons. While these instruments can be quite complex, they can always be broken down (and thus valued) as the sum of fairly standard securities.

In 1986, for example, Standard Oil of Ohio created an issue of oilindexed notes, in which the principal payment was a function of oil prices at maturity. The holder of a 1990 note received-in addition to a guaranteed principal amount— the value of 170 barrels of Light Sweet

23. The bond was floated on 31 May 2000 for 55 billion Chilean pesos. The bonds have a five-year maturity (to be repaid on 4 June 2005) and a coupon of 6.6 percent, and they are indexed to Chilean inflation. Most of the issue was acquired by Chilean institutional investors (75 percent), while the rest was placed among international investors. Chase Manhattan International Ltd. of New York acted as the director bank.

24. This is the so-called fear of floating (Calvo and Reinhart, 2002). In principle, one could think of an optimal amount of external peso debt at which the moral hazard problem is exactly offset by the fear-of-floating effect. In practice, such a mechanism may introduce significant policy uncertainty among investors. 
Oklahoma Crude Oil, with a price floor of $\$ 25$ and price ceiling of $\$ 40$. Investors essentially held a standard four-year bond that included a long call option with an exercise price of $\$ 25$ and a short call option with an exercise price of $\$ 40$.

The recent securitization of catastrophe insurance contracts in the United States similarly offers several important lessons. ${ }^{25}$ The first placements of these instruments faced numerous obstacles, ranging from investors' lack of understanding of their contingencies to the legal obstacles stemming from, for example, the great confusion on whether to classify these instruments as bonds or as insurance and hence on which institution should regulate them. Another lesson from the catastrophe risk experience is that these bonds will probably pay a significant premium early on, but this premium should come down rapidly. ${ }^{26}$ Since this declining path creates a natural incentive for a war of attrition in the private placement of these bonds, it reinforces the conclusion that the process needs to be started by the Chilean authorities or an international financial institution. ${ }^{27}$

\section{Final Remarks}

There is no reason to stop at financial markets. Once the contingent index has been created, contracts indexed to it can naturally arise. Chile's financial market already operates with an inflation index (the unidad de fomento, or UF), which has removed much of the uncertainty that microeconomic agents once experienced as a result of high, unstable inflation. The new contingency may be institutionalized to perform a similar role with regard to the uncertainty generated by financially amplified external shocks. For example, labor markets, such as minimum wages and temporary contracts, could be indexed to the contingent index to ease firms' financial difficulties during external crises. The structural fiscal surplus could also be indexed to free up financial resources to the private sector during those times.

Finally, regional interactions are also important. It may be worth giving up some of the benefits of specifically tailoring the instrument to Chilean needs in exchange for a much more liquid contingent bond

25. See Froot (1999).

26. The first catastrophe (or CAT) bonds, which were placed in 1997, initially paid a premium over nine times the expected loss. By 1999, that premium had steadily declined by nearly forty percent.

27. There is also some evidence that CAT options paid a lower initial excess premium than CAT bonds. See Cummins, Lalonde, and Phillips (2000). 
that includes other advanced emerging economies of the region, such as Argentina, Brazil, and Mexico. It may even prove advantageous to search for co-issuers beyond Latin America, with contingency needs not too distant from those of Chile. 


\section{REFERENCES}

Caballero, R.J. 1999. "Structural Volatility in Chile: A Policy Report." Washington: Inter-American Development Bank. Mimeographed.

. 2001. Macroeconomic Volatility in "Reformed" Latin America: Diagnosis and Policy Proposals. Washington: Inter-American Development Bank.

Caballero, R.J., and M. Hammour. 1998. "The Cost of Recessions Revisited: A Reverse Liquidationist View." Massachusetts Institute of Technology. Mimeographed.

Caballero, R.J., and A. Krishnamurthy. 2001a. "A Vertical Analysis of Crises and Central Bank Intervention." Massachusetts Institute of Technology. Mimeographed.

. 2001b. "Excessive Dollar Debt: Underinsurance and Domestic Financial Underdevelopment." Massachusetts Institute of Technology. Mimeographed.

_. 2001c. "International and Domestic Collateral Constraints in a Model of Emerging Market Crises." Journal of Monetary Economics 48(3): 513-48.

Calvo, G.A., and C.M. Reinhart. 2002. "Fear of Floating." Quarterly Journal of Economics 117(2): 379-408).

Cummins, J.D., D. Lalonde, and R.D. Phillips. 2000. "The Basis Risk of Catastrophic-Loss Index Securities.” Working paper 00-22-B-B. University of Pennsylvania, Wharton School.

Froot, K.A. 1999. The Financing of Catastrophe Risk. University of Chicago Press.

Marshall, I.L., and E.S. Silva. 1998. "Fluctuaciones del precio del cobre." Informe Macroeconómico para la Empresa 35 (September): 38-60.

Shiller, R. 1993. Macro Markets: Creating Institutions for Managing Society's Largest Economic Risks. Oxford University Press.

Tirole, J. 2000. "Notes on International Financial Architecture." L'Université de Toulouse. 
